\title{
Emotional Attachment, Performance, and Viability in Teams Collaborating with Embodied Physical Action (EPA) Robots
}

\author{
Sangseok You \\ School of Information \\ University of Michigan \\ 4377 North Quad \\ 105 S. State St. \\ Ann Arbor, MI 48109-1285 \\ Phone: 734-730-4124 \\ Fax: 734-615-3587 \\ sangyou@umich.edu \\ Lionel P. Robert Jr. \\ School of Information \\ University of Michigan \\ 4381 North Quad \\ 105 S. State St. \\ Ann Arbor, MI 48109-1285 \\ Phone: 734-764-5296 \\ Fax: 734-615-3587 \\ Iprobert@umich.edu
}

\begin{abstract}
Although teams are increasingly employing embodied physical action (EPA) robots as a collaborative technology to accomplish their work, we know very little about what makes such teams successful. This paper has two objectives: the first is to examine whether a team's emotional attachment to its robots can lead to better team performance and viability; the second is to determine whether robot and team identification can promote a team's emotional attachment to its robots. To achieve these objectives, we conducted a between-subjects experiment with 57 teams working with robots. Teams performed better and were more viable when they were emotionally attached to their robots. Both robot and team identification increased a team's emotional attachment to its robots. Results of this study have implications for collaboration using EPA robots specifically and for collaboration technology in general.
\end{abstract}

We would like to thank Michelle Carter, Jaime Windeler and Binny Samuel for their useful comments. 
Accepted to the Journal of the Association of Information Systems (JAIS) June 2017

\section{Introduction}

Robots have become deeply integrated into many types of teams (Robert \& You, 2014). These teams range from urban search-and-rescue teams to advanced surgical operations teams (Shah, Wiken, Williams, \& Breazeal, 2011; Zawieska \& Duffy, 2014). Many first-responder teams are paired with remote-control robots to help the teams perform both life-threatening and life-saving tasks (Kruijff et al., 2014). Members of search-and-rescue teams, for example, employ remote-control robots to perform such tasks as removing obstacles from dangerous areas (Burke, Murphy, Coovert, \& Riddle, 2004; Kruijff et al., 2014). Despite the gravity of the work performed by these teams, we know very little about how to facilitate better performance in teams working on collaborative tasks with robots.

The term robot is commonly used but its definition varies across many fields of study (Dautenhahn, 2013). In this paper, we define robots as technologies with both virtual and physical embodied actions. Scholars seem to agree that embodiment and representation of embodied behaviors are two characteristics that make robots different from other technologies (Dautenhahn, 2007; Krämer, von der Pütten, \& Eimler, 2012; Thrun, 2004). In this paper, we examine a specific type of robot we refer to as an embodied physical action (EPA) robot. EPA robots have physical embodiment, which invokes strong emotional responses that lead individuals to project identities and personalities onto them and treat them as human entities rather than as mere technological apparatuses (Groom \& Nass, 2007; Ramiller, 2016; Turkle, 2010). As a result, emotional responses to these robots can be similar to those invoked by humans (Groom \& Nass, 2007; Hiolle, Cañamero, Davila-Ross, \& Bard, 2012; Kidd, Taggart, \& Turkle, 2006; Rae, Takayama, \& Mutlu, 2012). We believe that the physical embodiment of EPA robots is likely to make emotional responses to them more central to understanding their impacts. Despite the fact that EPA robots are distinct among collaborative technologies, little if any IS research has been conducted in this area. This calls for IS scholars to expand the 
Accepted to the Journal of the Association of Information Systems (JAIS) June 2017

current theory of technologies to include new technologies that are becoming more available to teams (Suh, Kim, \& Suh, 2011).

Researchers have suggested that exploration of emotional attachment between teams and their technologies could be vital to understanding how to facilitate better teamwork in teams working with EPA robots (Carpenter, 2016; Groom \& Nass, 2007; Huang, Varnado, \& Gillan, 2013; Turkle, 2010). Emotional attachment to a technology is generally defined as an emotional bond or connection between individuals and their technology (Suh et al., 2011). When people are emotionally attached to their technology, they become more engaged in using the technology and enjoy the interaction with it more (Li, Browne, \& Chau, 2006). Increases in engagement and enjoyment while using a technology can lead to better performance on tasks involving that technology (Burton-Jones \& Straub Jr, 2006). Despite the potential importance of emotional attachment, many questions remain regarding whether emotional attachment can actually lead to better performance with technology in general and with EPA robots specifically.

Overall, this paper has two goals: (1) to examine whether a team's emotional attachment to its robots leads to more effective teamwork and (2) to understand how to promote emotional attachment to robots within such teams. In this study, robots represent a specific type of collaborative technology where collaboration takes place through embodied physical actions. To accomplish our two goals, we first examined whether a team's emotional attachment toward its robots would lead to increases in the team's performance and viability. Team performance and viability - the likelihood that the team will continue to exist - are both important assessments of effective teamwork (Balkundi \& Harrison, 2006). Second, we examined whether robot identification and team identification would promote a team's emotional attachment to its robots. To this end, we conducted a between-subjects experiment with 57 teams working with robots. Results indicate that a team's emotional attachment to its robots increases both the team's performance and its viability. In other words, teams working with robots performed better and 
were more viable when they were emotionally attached to their robots. In addition, both robot identification and team identification were associated with increases in a team's emotional attachment to its robots.

This study makes several contributions to the literature on collaborative technologies. One, this study takes the first step toward understanding how to facilitate better performance in teams collaborating through EPA robots. Research on this topic has been absent in the IS literature on collaborative technologies. Prior research in other fields has instead focused on how to promote more enjoyable interactions between individuals and their EPA robots and has ignored issues related to collaborative work and performance at the team or individual level (e.g., Groom, Takayama, Ochi, \& Nass, 2009; Sung, Guo, Grinter, \& Christensen, 2007). Yet robots, as a collaborative technology, are becoming increasingly important and central to many teams (Robert \& You, 2014), and performance outcomes are essential measures of success when teams are assembled to conduct tasks. Two, this study contributes by demonstrating that a team's emotional attachment to its EPA robots is an important facilitator of team performance and viability. Recent research on individual technology use highlights the potential role of emotional attachment (Suh et al., 2011), but no work has been done to examine the linkage between emotional attachment toward a technology and better performance with that technology at the team or individual level. In doing so, this study identifies a new performance antecedent associated with the use of collaborative technology that may also promote successful teamwork with other collaborative technologies. Three, this study contributes to the literature by introducing and exploring the role of identification in teams working with EPA robots. Identification has been linked to various performance outcomes (Pearsall \& Venkataramani, 2015; Robert, 2013), yet little is known about how it impacts performance through the use of a collaborative technology. In this study, two types of identification promoted emotional attachment toward robots, which in turn led to better team performance and more 
Accepted to the Journal of the Association of Information Systems (JAIS) June 2017

viability. As a result, this study sheds light on the potential for identification to be used to leverage team collaborative technologies other than EPA robots.

\section{Related Work}

In this section, we review several bodies of literature that inform and motivate our research. First, we provide a review of the literature on collaborative technologies and how this research has evolved. Then, we discuss the current IS literature on emotional attachment to technology. Finally, we highlight the absence of research directed at understanding the performance implications associated with a team's emotional attachment to its collaborative technology, particularly EPA robots.

\section{Collaborative Technology Research}

In this section, we present a framework that organizes the literature on collaborative technology into four streams. We define the term "collaborative technology" loosely, referring to any technology that allows individuals to engage or collaborate with other individuals. We would also like to first make several explicit statements about the framework: (1) These streams are not intended to be all-encompassing; such a framework would be beyond the scope of this paper. (2) These streams are also overlapping; in other words, collaborative technologies can and do fall into multiple streams. (3) We do not assume that one stream supersedes the others or that one is more important than the others; instead each stream represents a vibrant and ongoing set of research questions and scholars that are equally relevant and central to the IS community.

\section{Collaborative Systems as Complements to FTF}

Research in the first stream focuses on understanding how collaborative technologies could be used to supplement face-to-face interactions (Dennis, Wixom, \& Vandenberg, 2001; McLeod, 1992; Sharda, Barr, \& McDonnell, 1988). Much of this early research employs the term group 
support systems (GSS) to describe this set of collaborative technologies. GSS are collaborative technologies that enable teams to incorporate knowledge from different team members and help them make better decisions (Anson, Bostrom, \& Wynne, 1995). The use of GSS can lead to improved decision quality (e.g., Chidambaram \& Jones, 1993) and satisfaction (Benbasat \& Lim, 1993; Dennis et al., 2001), as well as reductions in decision time (e.g., Dennis, Nunamaker Jr, \& Vogel, 1990). Another example within this stream is research on electronic brainstorming systems (EBS) in collocated teams (see Dennis \& Reinicke, 2004) and on other collaborative technologies designed primarily to support communication processes in collocated teams (Bajwa et al., 2008). This research continues to provide new insights into how collaborative technologies can overcome communication barriers in collocated teams.

\section{Collaborative Systems as Substitutes to FTF}

Research in the second stream focuses on understanding the implications associated with having collaborative technologies as substitutes for face-to-face interactions. This stream of research examines both the advantages and disadvantages of collaborative technologies versus face-to-face interactions. Such studies employ media theories such as media richness (Daft \& Lengel, 1986; Dennis \& Kinney, 1998), channel expansion theory (Carlson \& Zmud, 1999), cognitive model of media choice (Robert \& Dennis, 2005), and media synchronicity (Dennis, Fuller, \& Valacich, 2008). For example, Dennis (1996) studied teams using a collaborative technology and teams meeting face-to-face without any technology to determine which set of teams shared and used more information (i.e. information integration). Similar work was done by Robert, Dennis, and Ahuja (2008). Other researchers within this stream have studied whether theories developed in face-to-face settings are more or less applicable to teams that rely entirely on collaborative technologies (e.g., Jarvenpaa, Knoll, \& Leidner, 1998). Overall, this stream of research is helping us understand when substituting collaborative technologies for face-to-face interactions is likely to be beneficial or problematic (see Dennis et al., 2008). 


\section{Adoption of Collaborative Systems}

More recently, IS scholars have begun to shift from understanding the implications associated with the employment of collaborative technologies to examining the adoption of such systems. Much of this work draws from Davis's Technology Acceptance Model (TAM) (Davis, 1986) and the Unified Model of Technology Acceptance and Use of Technology (UTAUT) (Venkatesh, Morris, Davis, \& Davis, 2003). TAM and UTAUT theoretically explain how attitudes and beliefs toward the use of a technology can, in part, predict whether someone will use that technology. Both models have been used successfully to predict an individual's use of technology across a wide variety of technologies, contexts, and users (Maruping, Bala, Venkatesh, \& Brown, 2017; Mortenson \& Vidgen, 2016).

Models based on TAM and UTAUT assert that the attitudes and beliefs that group members have toward a technology will predict whether the group will use that technology. Specifically, Brown, Dennis, and Venkatesh (2010) employed UTAUT to better understand a group adoption of a collaborative system. Park, Lee, and Yi (2011) also employed the UTAUT model by incorporating organizational facilitating conditions to better predict the adoption of a collaborative system. Kang, Lim, Kim, and Yang (2012) employed TAM to explain why individuals would choose to adopt a collaboration technology. However, Sarker and Valacich (2010) took an alternative approach to understanding the adoption of a collaborative system. They took a more non-reductionist view and used group valence as a key construct. They reported that group valence, a collective affect toward a team technology by the team members, predicted the team's adoption of the technology.

\section{Collaborative Systems as Embodied Action}

IS scholars are beginning to explore the impact of collaboration through embodied action. This research examines the potential of virtual worlds that feature virtual embodied actions through 


\section{Accepted to the Journal of the Association of Information Systems (JAIS) June 2017}

avatars in virtual environments (see Mennecke, Triplett, Hassall, Conde, \& Heer, 2011). Franceschi, Lee, Zanakis, and Hinds (2009) studied how engagement, and group and social presence facilitated better performance in learning tasks when individuals collaborated through avatars in Second Life. Saunders, Rutkowski, Van Genuchten, Vogel, and Orrego (2011) also examined brainstorming in Second Life to determine whether virtual space and place could impact perceptions of social presence, focused immersion, perceived ease of use, and enjoyment. They found strong support for the impact of virtual place but only partial support for the effects of virtual space. Also, Qiu and Benbasat (2010) reported that shopping recommendation systems that use human-like avatars increase shoppers' enjoyment and feelings of social presence regarding the system.

Unfortunately, the literature on collaboration through embodied action has exclusively focused on collaboration through embodied virtual action (EVA) robots and has ignored collaboration through EPA robots. This is problematic for several reasons. One, the overall research questions across these studies examining collaboration through virtual embodied actions are in large part based on how much virtual reality can mimic physical reality. For example, questions regarding the impacts of social presence, space, place, and similarity all examine the assertion that there are benefits when virtual reality better aligns with physical reality (e.g., Qiu \& Benbasat, 2010; Saunders et al., 2011). Yet, collaboration through embodied physical actions is already embedded within physical reality (Beane \& Orlikowski, 2015; Dourish, 2001). Therefore, attempts to enhance collaboration by making virtual reality more like physical reality might not prove to be as useful to studying collaboration through embodied physical actions.

Two, technologies' physical embodiment through physical instantiation makes individuals' interaction with technologies more salient and visceral (Fong, Nourbakhsh, \& Dautenhahn, 2003; Ramiller, 2016; Ziemke, 2003). This enhances the feelings associated with the technology, which leads to more emotional and social reactions and attitudes. For instance, Lee, Jung, Kim, 
and Kim (2006) studied individuals' reactions to pets presented in the form of either EVA robots or EPA robots. The authors found that individuals had a much stronger and positive affective reaction to EPA pet robots than to EVA pet robots (Lee et al., 2006). This finding implies that collaborative technologies that possess embodied physical action may provide a different experience from those that have virtually embodied actions. Yet we know very little about this emerging collaboration technology. Thus, our study focuses specifically on EPA robots, a distinct type of collaborative technology with physical embodiment. In doing so, we hope to expand the realm of IS theory by embracing EPA robots as a specific type of collaborative technology.

\section{Emotions, Emotional Attachment, and Technology Use}

Over the years, the literature in information systems (IS) has recognized the importance of emotions to understanding technology use (Beaudry \& Pinsonneault, 2010). Emotions can be defined as "an affective state[s] induced by or attributed to a specific stimulus" (Zhang, 2013, p. 251). The term usually reflects an individual's subjective feelings toward objects, environments, people, and events (Russell, 2003). Emotions are considered a subset of the broader term affect, which also encompasses moods (Ekkekakis, 2013; Zhang \& Li, 2005). Positive feelings such as enjoyment, satisfaction, and pleasure toward a particular technology were associated with more use of group support systems and mobile devices (Bhattacherjee, 2001; Chin \& Gopal, 1995; Kim, Chan, Chan, \& Gupta, 2004). On the other hand, anxiety as a negative emotion toward a technology has been found by many scholars to deter the use and adoption of technologies (Beaudry \& Pinsonneault, 2010; Brown, Fuller, \& Vician, 2004; Thatcher \& Perrewe, 2002; Venkatesh et al., 2003). Despite this, these studies have not paid much attention to the potential performance benefits of emotions (see Zhang, 2013 for a review).

Emotional attachment is often described as "an emotion-laden target-specific bond between a person and specific object" (Thomson, Maclnnis, \& Whan Park, 2005, p. 77). Scholars generally 
Accepted to the Journal of the Association of Information Systems (JAIS) June 2017

view emotional attachment as a basic human need that occurs naturally and unconsciously (Ainsworth, Blehar, Waters, \& Wall, 2014; Crowell, Fraley, \& Shaver, 2008; Thomson et al., 2005). Emotional attachment can occur between human and non-human objects including sports teams, products, and even work projects (Dainty et al., 2005; Funk \& James, 2006).

Research has been done on the emotional attachment humans develop with objects (Schouten \& McAlexander, 1995; Thomson et al., 2005). In marketing research, the process by which emotional attachment occurs is often described as beyond one's volitional control, which distinguishes it from other relevant concepts including loyalty and involvement, which imply cognitive decisions (Thomson et al., 2005). People also become emotionally attached to places, pets, brands, and work projects (Dainty et al., 2005; Kleine, Kleine, \& Allen, 1995; Schifferstein \& Zwartkruis-Pelgrim, 2008; Slater, 2001; Thomson et al., 2005). But people are particularly prone to becoming attached to consumer products (Mugge, Schoormans, \& Schifferstein, 2009; Schifferstein \& Zwartkruis-Pelgrim, 2008).

Emotional attachment to a technology has been shown to be an important predictor of intention to use that technology. This is based on the premise that the more emotionally attached individuals are to their technology, the more they want to use that technology and enjoy using that technology. Suh and colleagues (2011) found that individuals who identified themselves with their avatar were more emotionally attached to their avatar and had a greater intention to use it. Li, Browne, and Wetherbe (2006) also found that an individual's emotional bond to an ecommerce website was associated with higher levels of intention to continue to use that website. Similarly, Malhotra and Galletta (1999) found that attachment to an MS Exchange application led individuals to have a more positive attitude toward the technology and a greater intention to use it. Overall, research has consistently found a link between emotional attachment to a technology and intention to use that technology. 
The current research on emotional attachment to technology in the IS literature leaves several areas unexplored. First, to the best of our knowledge no study has examined the linkage between emotional attachment toward a technology and its impacts on the performance of individuals or teams using that technology. Nor has any researcher investigated the impact of a team's emotional attachment to its collaborative technology on the team's viability. Team performance and viability are at the core of effective teamwork with collaborative technologies. Therefore, answering these questions has the potential to advance our understanding of teamwork with technology in general. Second, our understanding is limited with regard to promoting emotional attachment to technology. Research has shown that emotional attachment is stronger when individuals believe that their technology is an extension of themselves (Kim et al., 2015). This can occur when individuals believe their technology is similar to themselves (Malhotra \& Galletta, 1999; Suh et al., 2011) or when they build or alter the technology (Groom \& Nass, 2007). However, technologies are often designed for task effectiveness, not to evoke feelings of similarity, and it is not always possible or desirable to have teams alter or build their technology. It then becomes important to find other approaches to promote emotional attachment to a technology. Finally, IS scholars have largely ignored the topic of emotional attachment to collaborative technologies that have embodied physical actions. Yet, it would appear that a team's emotional attachment to its technology is likely to be a vital component to understanding effective teamwork with such technologies (Carpenter, 2016; Groom \& Nass, 2007; Turkle, 2010).

\section{Research Model}

\section{Robots and Team Identification}

To understand emotional attachment to robots and the impact it may have on team outcomes, we developed a theoretical research model (see Figure 1). The research model draws from both identity and social identity theories. Identity theory is a theoretical approach to understanding 
the formation and alteration of individuals' identity based on their roles, relationships, and material objects (Stryker \& Burke, 2000). Identity theory helps to explain how someone's selfconcept is formed and can be extended (Stryker \& Burke, 2000). Social identity theory explains how individuals' identity is formed and altered by their membership in a social group (Tajfel \& Turner, 2004). Social identity theory explains how people come to see themselves as a member of a social group and what happens when they believe their membership is self-defining (Ashforth, Harrison, \& Corley, 2008). Identity theory helps to define the term me, while social identity theory helps to define the term we.

Our overarching theoretical model posits that teams can become emotionally attached to their robots either by identifying with the robots by extending their self-concept to include their robots or by identifying with the team that includes their robots. The former refers to identity theory while the latter refers to social identity theory. We draw from both identity and social identity theories for several reasons. First, research on identity and social identity theories has shown that identification facilitates emotional attachment to teams and artifacts (Belk, 1988; Bergami \& Bagozzi, 2000; Suh et al., 2011). Second, in teams working with robots, the robots and the team represent two potentially salient targets of identification that can be antecedents of emotional attachment to robots (Carter \& Grover, 2015). Third, by combining both theories this study takes a much more comprehensive approach to understanding emotional attachment and its subsequent outcomes for teams. In doing so, we answer the call by identity and social identity scholars who have called for a more integrative approach to understanding both theories (Cinoğlu \& Arıkan, 2012; Stryker \& Burke, 2000).

Based on identity and social identity theories, we developed a research model that proposes two instances of identification in teams working with robots - robot identification and team identification, as means to promote emotional attachment to the team's EPA robots. Robot identification occurs when team members view their robot as an extension of themselves by 
including the robot as a meaningful part of their self-concept. Building on the research of identity scholars like Carter and Grover (2015), we posit that emotional attachment to robots can occur through identification with the robot ${ }^{1}$. Team identification is important because members who are strongly identified with their team should be more emotionally attached to their robots. When individuals are identified with their team they can become emotionally attached to objects that represent their team (Gray \& Wert-Gray, 2012; Kwon, Trail, \& James, 2007). The research model proposes that both robot identification and team identification should separately and jointly increase a team's emotional attachment to its EPA robots. In turn, a team's emotional attachment to its EPA robots should lead to better team performance and viability. Figure 1 provides a summary of our arguments.

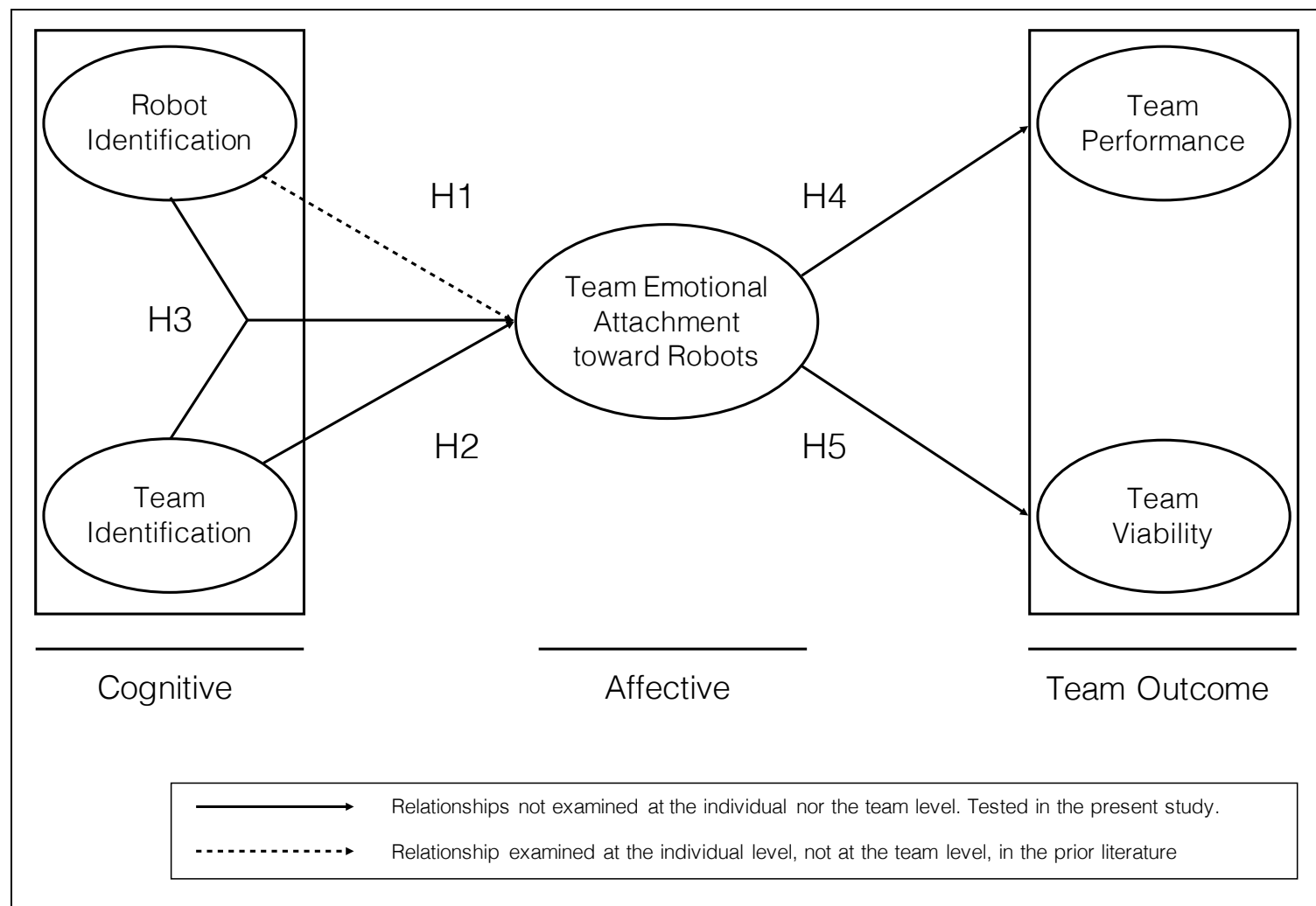

\section{Figure 1. Research Model}

1 We note that our conceptualization of robot identity is slightly different from Michelle Carter's work, in which IT identity is conceptualized as an individual incorporating the technology into his or her selfconcept. Our definition of robot identification is conceptualized as an individual extending his or her selfconcept to include the robot. 


\section{Robot Identification and Emotional Attachment}

We propose that robot identification can foster a team's emotional attachment to its EPA robots. Robot identification occurs through self-extension - the extending of one's self to include the robot (Groom et al., 2009). Self-extension is a psychological process where individuals project their identity to an external object (Belk, 1988). In this process, the object represents oneself and becomes an important component of oneself (i.e. "part of me") (Belk, 1988; Kiesler \& Kiesler, 2004). Identification through self-extension occurs when individuals believe the object and themselves share the same qualities (Belk, 1988, 2013; Connell \& Schau, 2013). Selfextension is a powerful mechanism of augmenting one's identity to external objects (Connell \& Schau, 2013). It has been used to represent identification with a company/product brand (Belk, 1988; Kim, Han, \& Park, 2001) and more recently with digital goods (Belk, 2013) and avatars (Suh et al., 2011; You \& Sundar, 2013).

Our argument about the impact of robot identification on emotional attachment is related those put forth in Carter and Grover's (2015) IT identity theory. IT identity theory is based largely on theories related to material identity (Carter \& Grover, 2015). Material identity asserts that individuals can become identified with a material object by including it as a part of their selfconcept (Dittmar, 2011). More specifically, IT identity theory argues that individuals can become identified with a particular information technology by including it in their self-concept (Aron \& Aron, 1997; Carter \& Grover, 2015). We become emotionally attached to things that make up our self-concept. However, in this paper identification occurs through self-extension. Whereas Carter and Grover (2015) viewed identification as the incorporating of IT into one's identity, selfextension represents the expansion of oneself to include IT.

Robot identification should lead to a strong emotional attachment to the robot because of the special meaning the robot has to the individual. In general, when team members identify with 
their robot, the robot is likely to hold a special meaning to them, which should lead to the formation of an emotional connection with that robot. When people identify with an object, they internalize the object by attaching a special meaning to their relationship with the object (Belk, 1988). These meanings are symbolic and are believed to be associated with values and qualities of their identity (Belk, 1988; Kiesler \& Kiesler, 2004). Identification with the object leads to the formation of an exclusive and unique relationship that distinguishes that object from others (Belk, 1988). An emotional bond is often established in the process (Mugge et al., 2009; Wallendorf \& Arnould, 1988). Identification through self-extension has been shown to promote emotional attachment with consumer products such as shoes, bicycles, and cars (Franke \& Piller, 2003; Schifferstein \& Zwartkruis-Pelgrim, 2008; Schultz, Kleine, \& Kernan, 1989) and with personal technological artifacts such as mobile phones (Carter, Grover, \& Thatcher, 2013; Vincent, 2006) and avatars (Belk, 2013; Kim et al., 2015). Likewise, in teams working with robots, when team members identify with their robot they should attach a special meaning to their relationship with it. This should lead them to have a stronger emotional attachment to the robot.

We believe that these effects are likely to materialize at the team level also ${ }^{2}$. The literature on sense-making and shared experiences tells us that individuals exposed to the same event can develop a shared interpretation of that event even if they do not experience that event together (Weick, 1995; Weick, Sutcliffe, \& Obstfeld, 2005). Shamir and Lapidot (2003) used this logic to explain how different employees in the same unit can develop similar levels of trust toward their supervisor. They found that being exposed to the same set of behaviors (i.e. supervisor's actions) in similar situations is likely to engender a similar response from each employee (i.e. trust or not in the same supervisor). This is not unlike the group responses from racial and

2 In this study, our approach to conceptualizing team phenomena is based on the aggregation of individual behavior, which is consistent with multi-level theory (Kozlowski \& Klein, 2000). However, there are other approaches to conceptualizing team-level phenomena that do not involve the aggregation of individual behavior. Please see Sarker and Valacich (2010) for an excellent discussion on this topic. 
Accepted to the Journal of the Association of Information Systems (JAIS) June 2017

gender minorities who have not experienced crucial events in life together but still develop similar responses and attitudes to such events (e.g., acts of discrimination; (Harrison, Price, \& Bell, 1998; Schmitt, Spears, \& Branscombe, 2003; Wright, Ursano, Bartone, \& Ingraham, 1990). This does not preclude the possibility of individual differences but instead can help to explain how different individuals can have similar reactions to events they have not shared in together, which can in turn lead to a group response. As such, we hypothesize the following:

H1: Robot identification increases a team's emotional attachment toward its EPA robots.

\section{Team Identification and Emotional Attachment}

We propose that team identification also increases a team's emotional attachment to its EPA robots. Team identification is typically defined as the extent to which individuals see their membership in their team as self-defining (Abrams \& Hogg, 2006; Hogg, Abrams, Otten, \& Hinkle, 2004). It represents the degree to which team members believe they share the same social identity with their team (Pearsall \& Venkataramani, 2015; Robert, 2013). Team identification explains the link between the need to belong and emotional attachment to people and objects that are linked to the same shared social identity (Baumeister \& Leary, 1995; Hogg \& Turner, 1985; Prentice, Miller, \& Lightdale, 1994). In fact, sharing a social identity has been shown to be a strong facilitator of emotional attachment in groups (Mikulincer, Orbach, \& lavnieli, 1998; Rom \& Mikulincer, 2003).

The link between team identification and emotional attachment in teams can be explained by sense-making (Huettermann, Doering, \& Boerner, 2016; Weick, 1995). The identification process often begins with a cognitive connection in which team members come to see themselves not as individuals but as a member of a team through an in-group/out-group process (Ashforth et al., 2008). But this process also has an affective component through which members begin to assess how much they value their membership (Van Der Vegt \& Bunderson, 
Accepted to the Journal of the Association of Information Systems (JAIS) June 2017

2005). This affective component involves assigning positive attributions to one's team membership and members (Ashforth et al., 2008; Huettermann et al., 2016). These positive attributions result from and lead to emotional bonds among team members (Janssen \& Huang, 2008; Wu, Tsai, Hung, \& others, 2012). This link has been found in both collocated and virtual teams (Carron, Bray, \& Eys, 2002; Evans \& Dion, 2012; Meyer, Becker, \& Van Dick, 2006; Tsui, Egan, \& O’Reilly, 1991).

We believe this same sense-making process can also lead teams with strong identification to develop strong emotional attachment to their robots. This is, in part, because the positive attributions associated with the team are not limited to other team members but instead can extend to objects that represent the team (Branscombe \& Wann, 1991). This is because, in part, objects are often strong representations of the values, norms, and beliefs associated with teams (Wu et al., 2012). These objects are branded with logos, colors, or images that invoke strong emotional bonds derived from identification (Smith, Graetz, \& Westerbeek, 2008). Emotional attachment to objects that represent one's team membership reinforces a feeling of belonging (Kwon et al., 2007). This phenomenon is easily observed in sports marketing, where groups of fans are often attached to their favorite team's apparel or other products bearing their team's logo (Gray \& Wert-Gray, 2012; Kwon \& Armstrong, 2004; Smith et al., 2008). Similarly, teams that are highly identified should be more emotionally attached to their robots for much the same reason. They are more likely to see EPA robots as a representation of the team. In turn, team members assign positive attributes to their robots, which should lead to strong emotional attachment to their robots.

Although researchers have not examined the link between team identification and a team's emotional attachment to its collaborative technology in general, and EPA robots specifically, we posit that such a link exists based upon the logic already described in this section and the empirical evidence that follows. Studies on service EPA robots in offices and hospitals have 
found that employees often develop strong emotional bonds toward EPA robots in their work group (Lee, Kiesler, Forlizzi, \& Rybski, 2012; Ljungblad, Kotrbova, Jacobsson, Cramer, \& Niechwiadowicz, 2012). In particular, Lee et al. (2012) showed that employees demonstrated various attachment behaviors such as giving names and putting clothes on a snack-delivery EPA robot once they accepted it as a part of their work environment. Additionally, studies examining the use of robots in military units found that units became attached to their EPA robots after they felt the EPA robots were a part of their unit (Scheutz, 2011). We believe this phenomenon occurs, in part, because the sense-making process involved in the team identification process leads to the creation of a strong emotional bond between teams and their robots. Theory and empirical evidence drawn from multiple research streams suggest a strong link between team identification and a team's emotional attachment to its robots.

H2: Team identification increases emotional attachment to robots.

\section{Moderation Effect between Robot Identification and Team Identification}

In addition to $\mathrm{H} 1$ and $\mathrm{H} 2$, we hypothesize that team identification should moderate the relationship between robot identification and a team's emotional attachment to its robots. As such, we expect that in the presence of both robot identification and team identification, team members will become more emotionally attached to their robots than with either of the two factors alone.

Research has found that team identification can provide the positive context to support other team phenomena (Janssen \& Huang, 2008; Richter, West, Van Dick, \& Dawson, 2006). For example, Van Der Vegt and Bunderson (2005) found that team identification determined the relationship between expertise diversity and learning. Expertise diversity was associated with increases in learning when teams had high levels of team identification but was associated with decreases in learning when team identification was low. Similarly, Somech, Desivilya, and 
Lidogoster (2009) found that higher levels of task interdependence were much more likely to lead to cooperation rather than conflict when teams were high in team identification. Many studies attribute this to the fact that the process of creating a shared identity can lead individuals to evaluate their interactions with team members and their overall team experience more positively (Hornsey \& Hogg, 2000; Tajfel \& Turner, 1979). This is precisely why we posit that team identification is likely to provide a facilitating context for the impacts of self-extension on emotional attachment.

Using similar logic, team identification should also moderate the relationship between the effects of robot identification and teams' emotional attachment to their EPA robots. We should expect robot identification to have a stronger relationship with a team's emotional attachment to its EPA robots when team identification is high. As mentioned, team identification can provide the positive context in which other team experiences occur (Richter et al., 2006). The more selfidentified teams are, the more likely they are to view their experiences more positively (Janssen \& Huang, 2008). In this context, the impact of self-extension on a team's emotional attachment to its EPA robot is likely to be bolstered by the positive context created by team identification. Therefore, when team members believe their EPA robots are an extension of themselves and also represent their team, they are likely to experience a stronger emotional connection with their EPA robots. Research has shown that objects can become more meaningful when they embody an extension both of oneself and of one's team membership (Funk \& James, 2006; Schultz et al., 1989). Therefore, we expect robot identification to have a stronger relationship with teams' emotional attachment to their robots when team identification is high.

H3: Team identification moderates the relationship between robot identification and a team's emotional attachment to its EPA robots in such a way that robot identification has a stronger relationship with a team's emotional attachment to its EPA robots when team identification is high. 
Accepted to the Journal of the Association of Information Systems (JAIS) June 2017

\section{Team Emotional Attachment toward its EPA Robots, and Team Performance}

Teams with strong emotional attachment to their EPA robots are likely to perform better because of their affective commitment. Affective commitment is viewed as the affective dimension of commitment that is based on an emotional response (Meyer, Paunonen, Gellatly, Goffin, \& Jackson, 1989). Affective commitment can be defined as a feeling of responsibility or obligation based on an emotional connection (Ellemers, Kortekaas, \& Ouwerkerk, 1999; Meyer et al., 1989). Affective commitment has been used to explain how emotional connections can lead team members to feel a sense of loss or gain based on how well their team performs (Meyer, Stanley, Herscovitch, \& Topolnytsky, 2002). In essence, teams high in affective commitment care more about accomplishing the team's task and this, in turn, has been shown to facilitate better team performance (Bishop, Scott, \& Burroughs, 2000; Porter \& Lilly, 1996). These teams also display several other positive characteristics as a result of their strong emotional attachment to their robots that can also promote team performance.

Affective commitment in teams has been associated with better social interactions among team members, which is often a key to better performance. Teams high in affective commitment are much more willing to put aside their differences to work together for the good of the team (Hoegl, Weinkauf, \& Gemuenden, 2004; Klein \& Mulvey, 1995). These teams are more likely to cooperate and less likely to engage in conflict (Porter \& Lilly, 1996). These team members are also much more willing to go above and beyond what is required when performing a task for one another (e.g., Becker, Billings, Eveleth, \& Gilbert, 1996; Meyer et al., 1989; Porter \& Lilly, 1996). These teams are also high in cohesion and trust, other important facilitators of team performance (Van Der Vegt \& Bunderson, 2005). A team's emotional attachment to its EPA robots should be positively associated with good social interactions driven by a strong commitment, which in turn should yield higher team performance (Meyer et al., 2002; Sonnentag \& Frese, 2003). 
Affective commitment has been widely shown to increase the performance of teams (Bishop et al., 2000; Meyer et al., 2002; Porter \& Lilly, 1996). For instance, Hoegl and colleagues (2004) found that such commitment to a project was strongly associated with increases in the performance of new-product development teams. Many other studies have provided consistent empirical evidence of this positive impact (e.g., a meta-analysis by Meyer et al., 2002). As such, a team's emotional attachment to its EPA robots should increase team performance by promoting strong affective commitment and better social interactions.

H4: A team's emotional attachment to its EPA robots is positively associated with increases in the team's performance with the EPA robots.

\section{Team Emotional Attachment and Team Viability}

Team viability is defined as the extent to which team members want to remain on the team in the future (Barrick, Stewart, Neubert, \& Mount, 1998). Research on teamwork has found strong connections between emotional attachment among team members and team viability (Balkundi \& Harrison, 2006). This has normally been explained by the fact that strong emotional ties among team members often result in a positive team experience (Foo, Sin, \& Yiong, 2006). The degree to which individuals find their team experience to be pleasant determines whether they would like to remain on the team (Bell \& Marentette, 2011; Sundstrom, De Meuse, \& Futrell, 1990). This is often used to explain why an individual's satisfaction and enjoyment with his or her team is positively related to team viability (Costa, Margarida Passos, \& Bakker, 2014; Ratcheva \& Vyakarnam, 2001).

Emotional attachment to a technology can contribute to individuals' positive assessment of their team experience. Researchers on individual use of technology have found a link between emotional attachment to a technology and enjoyment with using that technology (Read, Robertson, \& McQuilken, 2011). This is in part because when someone is emotionally attached 
to a technology, that person is much more likely to derive enjoyment while employing that technology (Roto \& Rautava, 2008). At least one study has found that enjoyment with the use of a technology can lead to positive attitudes toward the task involving that technology (Bruner \& Kumar, 2005). This finding provides evidence that enjoyment associated with the use of a particular technology can influence an individual's broader experiences involving that technology.

Taken together, when teams are emotionally attached to a technology used to accomplish their team task, they should also be more likely to enjoy their team experience and in turn want to remain on the team. Although we found no examples of this relationship in the literature, we believe that when team members are emotionally attached to their EPA robot they should be more likely to have a positive team experience and more likely to want to remain on their team. When this occurs, a team's emotional attachment to its EPA robots should increase the team's viability. The opposite, then, should also be true when team members are not emotionally attached to their robots. When teams are not emotionally attached to their robots, they should be less likely to want to remain on their team and team viability should decline. Therefore, we hypothesize:

H5: A team's emotional attachment to its robots is positively related to the team's viability.

\section{Method}

To test the hypotheses, we conducted a 2 (robot identification vs. no robot identification) $\times 2$ (team identification vs. no team identification) between-subjects experiment in a controlled lab setting. The experiment involved a team-based collaborative task. 
Accepted to the Journal of the Association of Information Systems (JAIS) June 2017

\section{Participants}

We recruited 114 participants from an online subject pool at a Midwestern university in the United States. The experimental pool includes more than 2,000 people, ranging from students to school employees, who voluntarily register across the campus. Because anyone older than 18 years can register for this pool, it includes people with a wide range of backgrounds, including age, gender, race, nationality, academic standing, major, and vocation. We used this pool in our experimental study; no compensation other than monetary reward was given because this experiment was not part of any class.

The mean age was 23 years (standard deviation $[S D]=5.3$ years); 51/114 $(44.7 \%)$ were men. Each human-robot team comprised two humans and two robots. Individual participants were randomly assigned to a team, for a total of 57 teams. Each human-robot team was also randomly assigned to one of four conditions: robot identification only (14 teams), team identification only (14 teams), both robot identification and team identification (14 teams), and neither of these treatments (control groups, 15 teams).

The random assignment was done automatically using an anonymous online sign-up sheet. Individual participants could choose only one experimental session without knowing who the other team member would be. We also asked participants whether they knew their team member before their experimental session and found that none of the teams had a prior relationship between members.

\section{Robots}

Two robots were used in each team in the experiment. These robots were adapted from the LEGO® Mindstorms ${ }^{\circledR}$ EV3 sets (Figure 2). The robots were capable of grasping small objects and were controlled with infrared remote controllers. The robots were designed to be able to 
speak (e.g., "Okay"), especially when grasping and releasing objects, in this case water bottles. All robots were identical in form and functionality.

LEGO Mindstorms have been widely used in many studies of human-robot interaction (e.g., Groom et al., 2009; Li, Rau, \& Li, 2010). Using Mindstorms, researchers are able to create a robot specifically suitable to their research interest, because Mindstorms allows a wide variety of design in both robot appearance and program. We were able to design a robot capable of performing just the intended experimental tasks, in this case grabbing and releasing a small object and moving around by remote control. In addition, it is easy for most people to build an object with LEGO blocks. This study involved building a robot as a means to manipulate one of the independent variables - robot identification. Participants were comfortable assembling a few blocks to complete their robots by following the provided instructions.

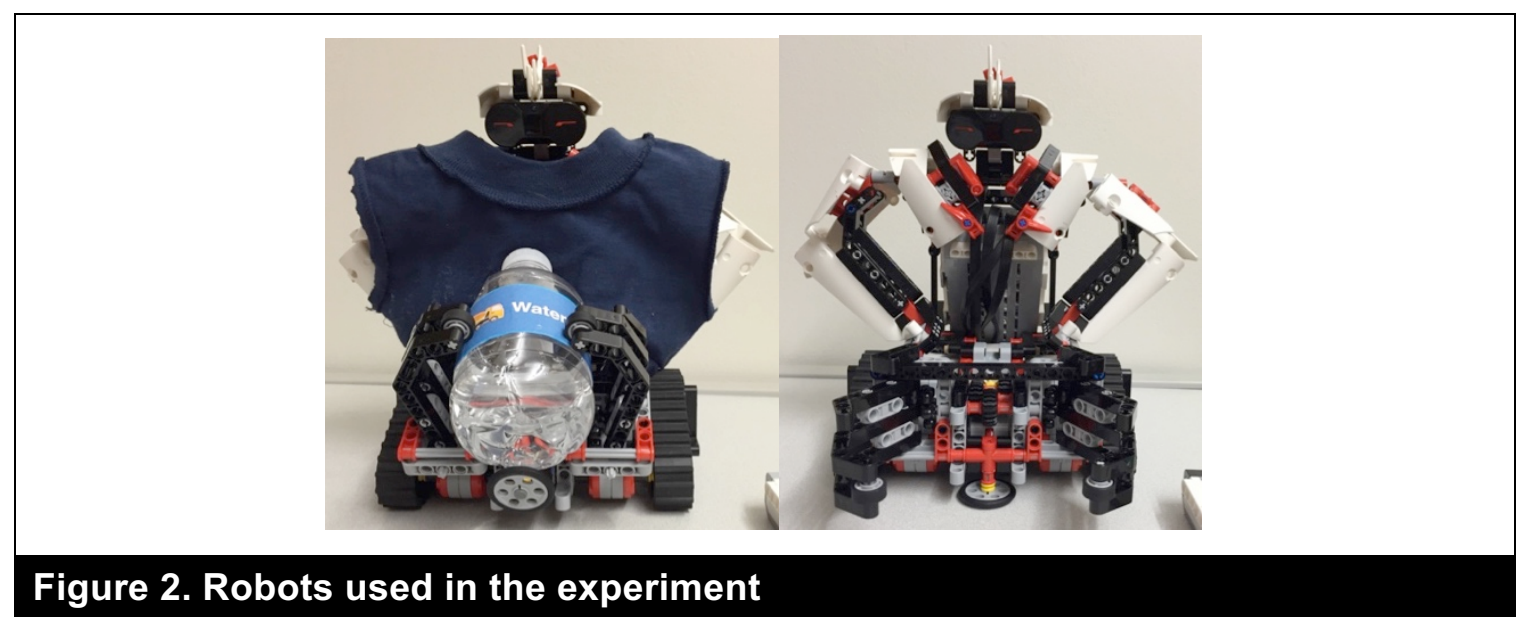

\section{Experimental Task}

The objective of the task was to deliver five plastic water bottles $(236 \mathrm{ml})$ along the designated course by controlling robots using a remote controller. The task course was created with cardboard ( 0.44 meters $\times 2.91$ meters $)$. Eight plastic cones taped on the cardboard were used as obstacles (Figure 3). 


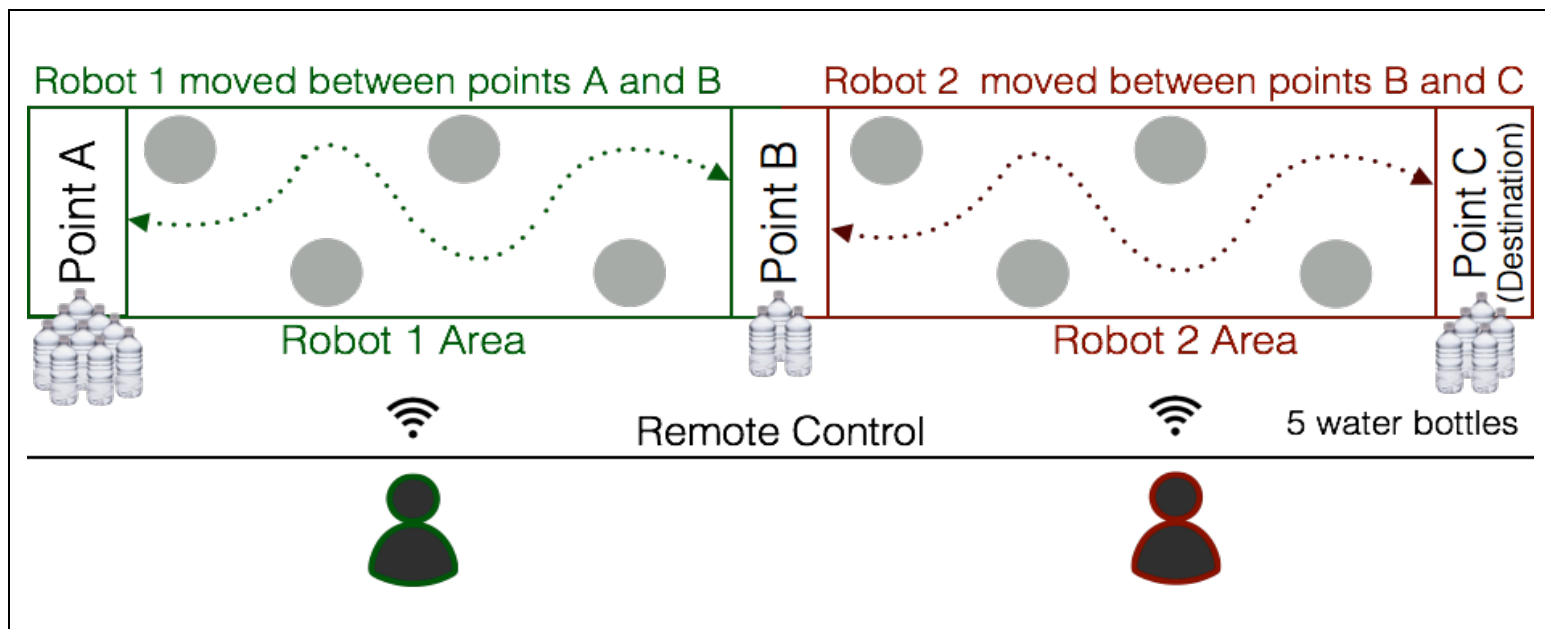

Figure 3. Experimental Task Setting

The task was intended to be interdependent between the route of the first robot (point $A$ to point B) and the route of the second robot (point B to point C). The first participant in each team used the first robot (robot 1) to pick up water bottles from point $A$ and drop them at point $B$, avoiding the obstacles. The second participant in a team picked up the water bottles using the second robot (robot 2) at point $B$ and delivered them to point $C$, the final destination. The task was completed as soon as all the five water bottles arrived at point $C$. The second team member could not deliver any water bottle until the first team member delivered at least one water bottle to point B. As such, one team member was not able to complete the task without the cooperation of the other team member.

Each team competed against all the other teams for the best time. All participants were given \$20 upon completion of the session regardless of their performance. All participants were informed that an additional monetary award would be given to the three best-performing teams in the study: the team with the fastest delivery time would receive an additional $\$ 100$; the second- and third-place teams would receive an additional $\$ 40$ and $\$ 20$, respectively.

There were three rules in the experimental task. First, participants were not allowed to trade robots; this was to ensure that all participants, particularly those who built their robot, interacted 
with only one robot throughout the session. Second, robots could only move around within their specified cardboard work area. For instance, the work area for the first robot was between points $A$ and $B$, whereas the work area for the second robot was between points $B$ and $C$. Last, humans were not allowed to touch and move the water bottles during the task. They were required to stay outside the work area and to control their robots using remote controllers.

The experimental task was designed to accomplish two objectives. First, the task imitated common types of tasks involving robots, such as moving objects using a remote controller. For instance, robots are often controlled by a human pilot to fetch and deliver objects in warehouses or to retrieve injured people in urban search-and-rescue (USAR) operations (Burke et al., 2004; Frizell, 2014). Additionally, moving objects while avoiding obstacles is one of the core tasks in the DARPA Robotics Challenge (Yanco et al., 2015). Second, the task was designed to be collaborative for two people. The task was sequentially interdependent because two individuals worked on their own part of a whole task but needed the other to complete it, and the task yielded the team performance by measuring task duration (Thompson, 2011). This task allowed individuals to interact with their own robots in fulfilling their portion of the work as well as communicate with their teammate for strategizing as a team.

\section{Procedure}

The experiment used two rooms: a treatment room and a task room. In the treatment room, participants were greeted, briefed, and asked to answer questionnaires. The task room had a single purpose - fulfillment of the experimental task.

When entering the treatment room, participants were welcomed and provided with a brief introduction of the study. They were then given consent forms. Once they consented, participants were asked to answer a short pre-questionnaire. The pre-questionnaire included questions on demographics and individual traits such as previous knowledge of Mindstorms. 
Then, participants were given instructions about the experimental task and about how to control the robot using a remote controller. After reading the written instructions, participants watched video instructions that contained the same content as the written ones. These videos included audio-visual descriptions of the task and how to control the robot.

Next, participants went through the experimental treatments based on the condition that they were randomly assigned to. Participants who were assigned to the robot identification condition were provided with the building instructions and asked to build their robot. Participants who were assigned to team identification treatment were asked to wear a uniform and choose a team name. Participants who were assigned to the condition with both robot identification and team identification treatments were instructed to build the robot first and then wear a uniform and choose a team name. In the control condition, without any treatments, participants were guided directly to the next step.

The next step was the experimental task - delivering five water bottles. Participants moved to the task room carrying their robots themselves. In the task room, they were asked to activate the robots. All participants were then given two types of training. First, free-movement training was provided. For approximately 2-3 minutes, participants were allowed to freely operate their robots outside the work area. Second, participants were allowed two untimed trial runs; during this training, participants practiced delivering five water bottles as a team from points $A$ to $C$. Task time was not recorded in these two trial runs. After finishing the training, participants completed the timed task. The time it took to deliver all five water bottles to point $\mathrm{C}$ was measured using a stopwatch. Participants were shown their team's time right after the timed task was completed. Records of other teams and the average performance time were never given, even if participants asked. The duration of interaction with robots in the task room was 25-30 minutes. 
Accepted to the Journal of the Association of Information Systems (JAIS) June 2017

Upon the completion of the experimental task, participants returned to the treatment room and answered a post-questionnaire. Then participants were debriefed, paid, and dismissed.

\section{Independent Variables and Experimental Manipulations}

\section{Robot Identification}

The independent variable robot identification had two levels: robot identification and no robot identification. In the robot identification condition, participants were asked to assemble the head compartment and integrate the head onto the pre-built body of the robot. Identical bricks and instructions were given to both participants on each team in this condition. Each participant was asked to build the head of the robot that he or she was to use for the experimental task. They were informed that the building portion of the study was not a test and they were allowed to take as long as they wanted. All participants in the building condition completed the building process. The average building time was 8 minutes 29 seconds.

We measured self-extension to ensure the effectiveness of the manipulation of robot identification. Self-extension, defined as the degree to which an individual perceives an object as an extension of the self, can elicit strong feelings of emotional attachment to an object (Pierce, Kostova, \& Dirks, 2001; Van Dyne \& Pierce, 2004). Team members can experience self-extension from activities like building, creating, and assembling an object (Schifferstein \& Zwartkruis-Pelgrim, 2008). This phenomenon occurs through investing their time, energy, and attention into the object, which they then view as being more authentic and unique than other objects (Csikszentmihalyi \& Halton, 1981; Littrell, Anderson, \& Brown, 1993; Mugge et al., 2009). Several studies have shown that building one's own technology, such as avatars and robots, leads to the belief that the technology is an extension of oneself and thus results in strong emotional attachment (Ducheneaut, Wen, Yee, \& Wadley, 2009; Groom et al., 2009; You \& Sundar, 2013). When team members build objects, these objects have special meaning, and 
individuals often demonstrate strong preference for these objects over objects they have not built or altered themselves (Wallendorf \& Arnould, 1988).

The scale of self-extension was designed to capture the degree to which individual participants reflected their identities to their robots by building them. The scale consisted of seven items adapted from Schifferstein and Zwartkruis-Pelgrim (2008) and was measured using 5-point Likert scale $(1=$ strongly disagree to $5=$ strongly agree). An example item is "If I were describing myself to my team members, this robot would likely be something I would mention." The scale reliability was .89 and justified for aggregation, $\operatorname{ICC}(1)=.26$.

\section{Team Identification}

Uniforms and team names were used to manipulate another independent variable, team identification. Participants in the team identification treatment were asked to come up with a team name. After participants finished discussing the team name, the experimenter provided uniforms for the participants and the robots. Participants were given basketball jerseys with the university's name printed on the front as well as 6-month infant clothes that had the university's name printed on the front. Participants in this treatment were asked to wear the uniforms and put the infant clothes on their robots.

The effectiveness of the team identification manipulation was checked by testing the degree to which participants identified themselves with their team. Perceived team identification was determined by an index of six items including "I considered myself a part of this team," adapted from Brown, Condor, Mathews, Wade, and Williams (1986). The scale was measured using a 5point Likert scale. The scale was reliable, .94, and justified for aggregation, intra-class coefficient or $\operatorname{ICC}(1)=.33$.

The manipulation checks for the independent variables were done using a $t$-test. Manipulations for both independent variables were successful. Self-extension was higher in teams that built 
their robots $(M=3.08, S D=.56)$ than in teams that did not $(M=2.74, S D=.64), t(55)=2.15, p$ $<.05$. Perceived team identification was higher in teams with team identification treatment $(M=$ $4.30, S D=.49)$ than in teams without team identification treatment $(M=4.03, S D=.50), t(55)=$ $2.07, p<.05$

\section{Measurements}

\section{Emotional Attachment to Robots}

Emotional attachment was measured to capture the degree to which participants were attached to the robot that they used for the task. The scale of emotional attachment consisted of seven items adapted from Schifferstein and Zwartkruis-Pelgrim (2008) using a 5-point Likert scale $(1=$ strongly disagree to $5=$ strongly agree). The scale included "This robot is dear to me" and "I feel emotionally connected to this robot." The reliability of the scale was .97 .

It should be noted that emotional attachment was measured as a team-level construct. Individual participants rated emotional attachment to their own robot. Then the ratings by two participants in a team were averaged for the aggregation into a team level. Team-level constructs are often created by averaging individual responses (e.g., see Kozlowski \& Klein, 2000). This is acceptable as long as group membership explains a significant amount of the construct's variance (Bliese, 2000). To determine this, we measured the construct's intra-class correlation (ICC). ICCs over .10 are normally used to justify the aggregation of individual responses to the team level (Bliese, 2000). The ICC score for emotional attachment was .42, providing justification for the averaging of individual responses. Although averaging individual responses is not without its shortcomings, it does allow us to create a team-level construct that aligns with the other team constructs in our model. 
Accepted to the Journal of the Association of Information Systems (JAIS) June 2017

\section{Team Performance}

Team performance was measured as task duration in seconds. The shorter the time was, the better the performance. The task was considered completed as soon as the fifth water bottle was delivered to point $\mathrm{C}$.

\section{Team Viability}

Team viability was determined using an index of five items adapted from Gardner and Kwan (2012) and measured using a 6-point Likert scale. Example items were "This team including the robots would perform well together in the future" and "If given a choice, I would prefer to continue working in this team including the robots." Reliability of the scale was .95. Team viability was justified for aggregation to the team-level construct, with $\operatorname{ICC}(1)=.49$.

\section{Control Variables}

We used several control variables, including participants' demographic information and knowledge and experience relevant to robots. Age, gender, and racial diversity were examined across all conditions, but none of these data showed statistically significant mean differences among our treatment and control conditions. The control variables regarding robots and relevant technologies, which are included in our analysis, are described in the next three sections.

\section{Negative Attitudes toward Robots (NARS)}

Researchers in human-robot interaction have found that general attitudes toward robots often determine attitudes and perceptions toward a particular robot and predict emotional bonds between the user and the robot (Broadbent, Stafford, \& MacDonald, 2009; You, Nie, Suh, \& Sundar, 2011). Negative attitudes toward robots (NARS) was measured to capture team members' general attitudes and feelings about communicating, working, and living with robots in daily life (Nomura, Suzuki, Kanda, \& Kato, 2006). The NARS scale consisted of six items adopted from Nomura et al. (2006) and measured using a 5-point Likert scale. Example items 
Accepted to the Journal of the Association of Information Systems (JAIS) June 2017

were "I would feel uneasy if I were given a job where I had to use robots" and "I would feel nervous operating a robot in front of other people." Reliability of the scale was .88 and ICC(1) was .63 for aggregation to the team level.

\section{Knowledge on Technology Relevant to Robots}

We measured teams' general knowledge and expertise on relevant technologies to robots through three self-assessment items. The scale consisted of three questions asking participants' levels of knowledge on computer programming, robotics, and artificial intelligence (AI). The questions were based on a 5-point Likert scale $(1=$ none, $3=$ below average, and $5=$ professional). Reliability of the scale was .86 . The scale showed $\operatorname{ICC}(1)=.48$ for aggregation to the team level.

\section{Previous Experience with LEGO Mindstorms}

We measured prior experience with LEGO Mindstorms to control for potential influence of team members' familiarity with LEGO products and Mindstorms systems on perception toward robots and team performance. The scale consisted of two items and participants were asked to indicate the degree to which they had been exposed to LEGO products and Mindstorms in their lives before the experiment, based on a 5 -point Likert scale $(1=$ never, $3=$ sometimes, and $5=$ all of the time). Reliability of the scale was .71 and $\operatorname{ICC}(1)=.55$ for aggregation to the team level.

\section{Analysis and Results}

We employed a partial least squares (PLS) approach to analyze the data using SmartPLS 3.2. Given the nature of our model and the structure of the data, we chose PLS to conduct a structural model test at the team level that included latent variables.

\section{Measurement Validity}

When testing models using PLS, both the measurement model and the structural model can be obtained as an outcome of the analysis. All variables, including emotional attachment, team 
viability, NARS, knowledge on relevant technology, and previous experience with LEGO Mindstorms, were modeled as reflective constructs.

To ensure discriminant validity between the variables, we report results of factor analysis as an outcome of PLS analysis. Table 1 shows that all items except one loaded at least .7 or above on each of their constructs, and indicated no cross-loadings above .4; the exception was the first item on previous experience of with LEGO Mindstorms. This is a clear indication of discriminant and convergent validity of the measurable dependent variables (Fornell \& Larcker, 1981). However, despite the low factor loadings of .46 , we decided to include the first item in previous experience with LEGO Mindstorms. Two items in the scale were strongly correlated (Pearson's $r$ $=.58, p<.01$ ), which warrants convergent validity of the items in the variable.

\section{Table 1: PLS Factor Loadings and Cross-loadings}

\begin{tabular}{|c|c|c|c|c|c|}
\hline \multirow{2}{*}{ Items } & \multicolumn{5}{|c|}{ Component } \\
\hline & 1 & 2 & 3 & 4 & 5 \\
\hline Emotional Attachment 1 & .95 & & & & \\
\hline Emotional Attachment 2 & .91 & & & & \\
\hline Emotional Attachment 3 & .91 & & & & \\
\hline Emotional Attachment 4 & .88 & & & & \\
\hline Emotional Attachment 5 & .91 & & & & \\
\hline Emotional Attachment 6 & .94 & & & & \\
\hline Emotional Attachment 7 & .88 & & & & \\
\hline Team Viability 1 & & .84 & & & \\
\hline Team Viability 2 & & .94 & & & \\
\hline Team Viability 3 & & .94 & & & \\
\hline Team Viability 4 & & .90 & & & \\
\hline Team Viability 5 & & .95 & & & \\
\hline Negative Attitudes Toward Robots 1 & & & .78 & & \\
\hline Negative Attitudes Toward Robots 2 & & & .72 & & \\
\hline Negative Attitudes Toward Robots 3 & & & .78 & & \\
\hline Negative Attitudes Toward Robots 4 & & & .74 & & \\
\hline Negative Attitudes Toward Robots 5 & & & .85 & & \\
\hline Negative Attitudes Toward Robots 6 & & & .84 & & \\
\hline Knowledge on Relevant Technology 1 (Programming) & & & & .92 & \\
\hline Knowledge on Relevant Technology 2 (Robotics) & & & & .82 & \\
\hline Knowledge on Relevant Technology $3(\mathrm{Al})$ & & & & .91 & \\
\hline Previous Experience with LEGO Mindstorms 1 & & & & & .46 \\
\hline Previous Experience with LEGO Mindstorms 2 & & & & & .99 \\
\hline
\end{tabular}


Additionally, correlations between constructs included in our research model were tested to assess discriminant and convergent validity (Table 2). Convergent validity of a construct is normally assessed based on the square root of the average variance extracted (AVE) values. When the AVE value is above .50 , the variance explained by the construct is greater than the variance explained by measurement error, which indicates evidence of convergent validity of the construct. The AVEs of emotional attachment and team viability were .83 and .84 , respectively, which are above .50 as recommended by Fornell and Larcker (1981). Then the correlations of all constructs were compared with the square root of AVE values of emotional attachment and team viability. The correlation matrix, shown in Table 2, indicates that correlations among all constructs were well below the square root of AVEs, which is further evidence of discriminant validity among dependent measures. Additionally, all latent variables indicate internal composite reliability (ICR) greater than .70, which demonstrates internal consistency (Fornell \& Larcker, 1981).

Table 2: Descriptive Statistics, Correlations among Constructs, Internal Composite Reliability (ICR), and Average Varience Extracted (AVE)

\begin{tabular}{|c|c|c|c|c|c|c|c|c|c|c|}
\hline & Mean & SD & 1 & 2 & 3 & 4 & 5 & 6 & 7 & 8 \\
\hline 1. Robot Identification & .49 & .50 & NA & & & & & & & \\
\hline 2. Team Identification & .49 & .50 & .02 & NA & & & & & & \\
\hline 3. Emotional Attachment & 2.82 & .79 & $.31^{*}$ & $.43^{* *}$ & $.91(.97)$ & & & & & \\
\hline 4. Team Viability & 4.37 & .69 & .05 & $.33^{*}$ & $.44^{\star *}$ & $.92(.96)$ & & & & \\
\hline 5. Performance & 259.26 & 49.74 & .00 & $-.33^{*}$ & $-.32^{*}$ & $-.39^{* *}$ & NA & & & \\
\hline 6. Negative Attitudes Toward Robots & 2.44 & .54 & .09 & .17 & .06 & $-.30^{\star *}$ & .18 & $.79(.91)$ & & \\
\hline 7. Knowledge on Relevant Technology & 2.17 & .64 & -.09 & -.15 & -.23 & -.04 & -.17 & $-.37^{\star *}$ & $.88(.91)$ & \\
\hline $\begin{array}{l}\text { 8. Previous Experience with Lego } \\
\text { Mindstorms }\end{array}$ & 1.8 & .46 & .22 & -.17 & -.02 & .00 & -.11 & -.21 & $.35^{*}$ & $.77(.73)$ \\
\hline
\end{tabular}


Accepted to the Journal of the Association of Information Systems (JAIS) June 2017

\section{Hypothesis Testing}

The hypotheses were tested by assessing the significance of the paths in the structural model. In this study, we employed the standard bootstrapping procedure by resampling 1,000 subsamples using SmartPLS 3.2. The highest value of variance inflation factors (VIF) in our model was 1.33 , which is well below the commonly agreed threshold of 10 . This demonstrates the less likelihood of multicollinearity influencing results of the model testing. Figure 4 shows results of the model testing, in which $R^{2}$ indicates the variance explained and $B$ indicates the standardized path coefficients of each path in the structural model.

$\mathrm{H} 1$ posited that robot identification increases a team's emotional attachment to robots. The hypothesis was supported by the results of the model $(B=.31, p<.01)$. H2, team identification increases a team's emotional attachment to robots, was also supported $(B=.43, p<.001)$. In $H 3$, we hypothesized an interaction effect between robot identification and team identification on team emotional attachment. The path was only marginally significant and did not support H3 ( $=-.18, p=.09$ ). However, we found strong support for positive impacts of emotional attachment to robots on team outcomes. As $\mathrm{H} 4$ posited, team emotional attachment to robots increased team performance by shortening task completion time $(B=-.34, p<.01)$. Because team performance was obtained by measuring time duration for a team to complete the task, the shorter time represents the better performance. Also, team viability was increased by a team's emotional attachment to robots $(B=.47, p<.001)$, which was consistent with H5. A summary of the hypothesis testing is shown in Table 3. 


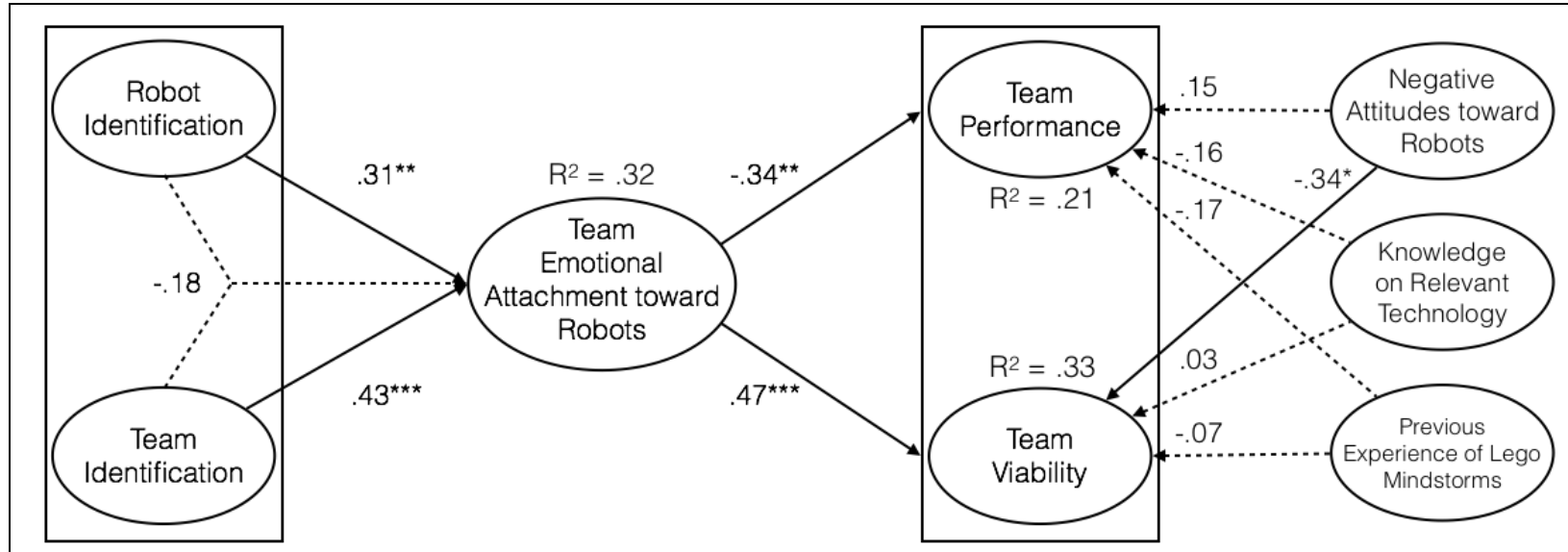

Note: $N=57 ;{ }^{*} p<.05,{ }^{* *} p<.01,{ }^{* *} p<.001$. Statistically significant paths are indicated as solid lines, where non-significant pants are indicated as dotted lines.

\section{Figure 4. Results of PLS Structural Model}

\begin{tabular}{|l|c|}
\hline \multicolumn{1}{|c|}{ Table 3: Results of Hypothesis Testing } & Results \\
\hline H1) Robot Identification $\rightarrow$ Emotional Attachment & Supported \\
\hline H2) Team Identification $\rightarrow$ Emotional Attachment & Supported \\
\hline H3) Interaction Effects $\rightarrow$ Emotional Attachment & Not Supported \\
\hline H4) Emotional Attachment $\rightarrow$ Team Performance & Supported \\
\hline H5) Emotional Attachment $\rightarrow$ Team Viability & Supported \\
\hline
\end{tabular}

\section{Discussion}

Our goal in this research was to examine the impact of a team's emotional attachment to its robots on the team's performance and viability and to identify ways to facilitate a team's emotional attachment to its robots. We found that a team's emotional attachment to its EPA robots was associated with better team performance and higher team viability. Both robot identification and team identification were found to promote a team's emotional attachment to its EPA robots. But team identification did not moderate the relationship between robot identification and a team's emotional attachment to its EPA robots. Taken together, these findings highlight the importance of emotional attachment in teams working with EPA robots. 
Contributions to the literature, theoretical implications, and study limitations are detailed in the next section.

Before we begin discussing the implications of our work, we should also note that hypothesis 3 was only marginally significant $(p=0.09)$. However, we did plot the moderation effect in an attempt to examine the trend of the effect based on results of an ANCOVA analysis including the control variables, $F(1,50)=1.84, p=.18$. Figure 5 shows the interaction effects of both interventions, which acted more like substitutes. Contrary to our previous assertion, team identification actually seems to weaken the relationship between robot identification and a team's emotional attachment to its robots. This implies that teams do not benefit more when combining both interventions.

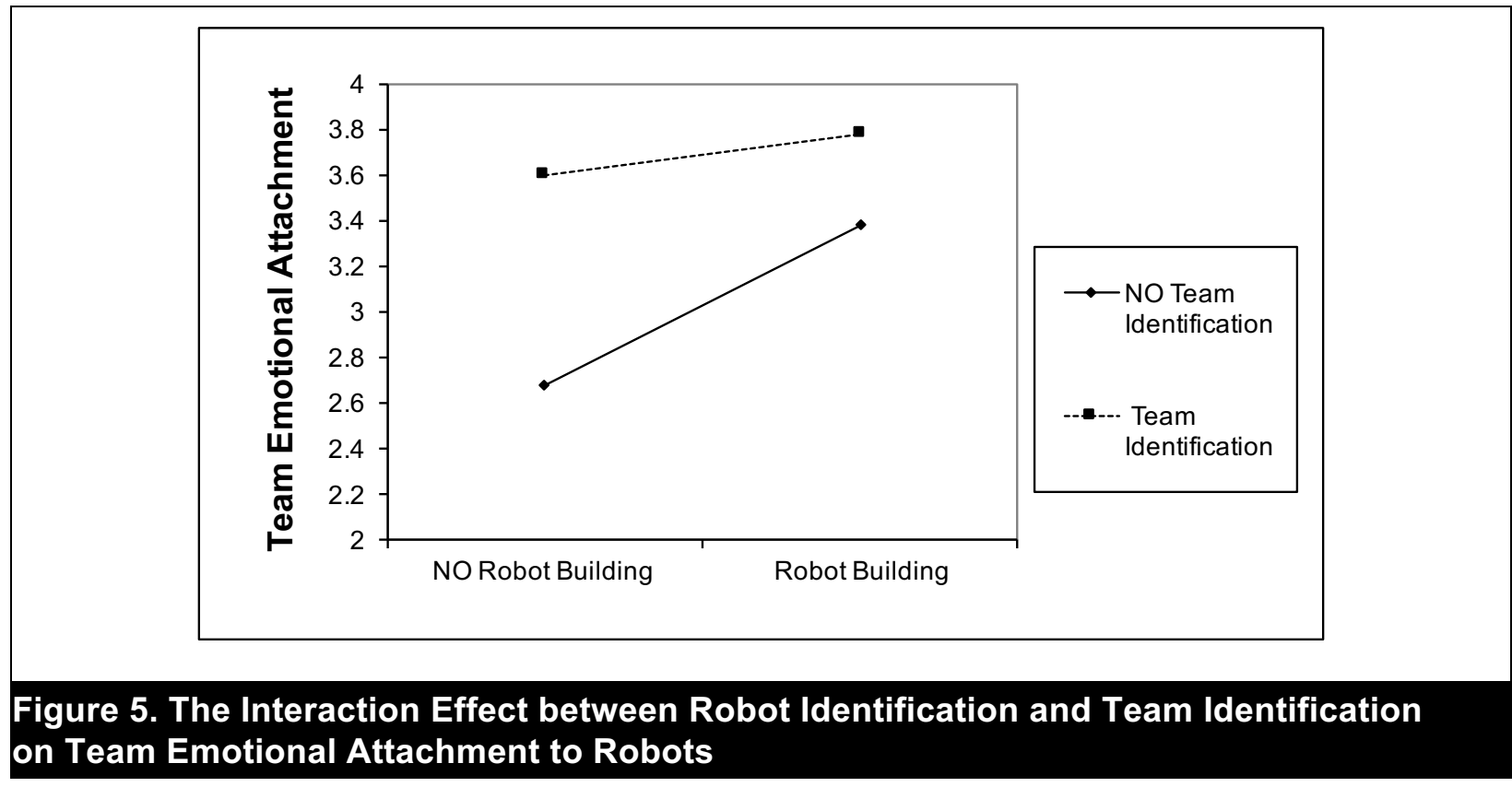

\section{Contributions}

Overall, this study contributes to the literature on collaborative technologies in a new area involving collaboration through embodied physical action (EPA) robots. First, this study calls attention to the importance of promoting more effective teamwork in teams working with an 
emerging collaboration technology, EPA robots. Every day the use of such robots to accomplish teamwork is increasing, and in many cases these robots are at the core of the work being performed (Robert \& You, 2014). Many of these teams engage in life-saving activities (Burke et al., 2004; Zawieska \& Duffy, 2014). Although researchers are beginning to investigate collaboration through EVA robots, no such efforts have been undertaken to understand collaboration through EPA robots. This study begins to address this issue by directly examining collaboration through EPA robots.

Second, this study identifies a new antecedent associated with effective collaboration through EPA robots, specifically with regard to team performance and viability. When teams are emotionally attached to their robots, theories of affective commitment posit that such teams should be more devoted to accomplishing their task well and that team members should be more willing to remain with the team. Our results provide evidence of both of these impacts being derived from teams' emotional attachment to their robots. Therefore, this study identifies a team's emotional attachment to its EPA robots as a vital and important predictor of both the team's performance and its viability.

This study demonstrates that a group's emotional attachment to a technology can lead to better performance with that technology. Although this finding is novel in the context of group technology use, others have found a similar link between emotional attachment to an organization and the performance of its employees (Chun, Shin, Choi, \& Kim, 2013; Meyer et al., 2002). Yet, establishing this connection in this new context is particularly important. As robots move from the factory floor to a much more ubiquitous presence in our society, establishing this link provides a vital starting point for a broader investigation into the use of robots. If emotional attachment is not pertinent to understanding performance with robots, this would be important to know sooner rather than later. 
Third, this study highlights a new approach to promoting emotional attachment in teams working with EPA robots: team identification. In our study, team identification was positively associated with increases in a team's emotional attachment with its EPA robots. Previous researchers have focused on some form of self-extension through robot identification to support emotional attachment to EPA robots (Groom et al., 2009). That approach was also found to be important in this study. However, individuals may not have the expertise needed to engage in such an approach, nor would the team want to risk compromising the quality of its EPA robots by having unqualified people attempting to build them. Therefore, it is vital to find alternatives to promoting emotional attachment. As such, this study contributes to the literature by identifying a new facilitator of emotional attachment to robots.

Fourth, this study confirms the positive influence of robot identification as an intervention to promote emotional attachment to teams as well as individuals. Although robot identification has increased emotional attachment to robots among individuals (Groom et al., 2009; Huang et al., 2013), prior research has not examined its effect on teams. Yet many teams are employing robots to perform their work (Robert \& You, 2014). Our results show that teams' emotional attachment to their robots increased when the teams underwent robot-building activities. Therefore, our results extend the positive impact of robot identification to teams.

Finally, our findings on robot identification and team identification answer the call for more research on the use of interventions in understanding technology use (Venkatesh \& Bala, 2008). Interventions offer IS scholars the opportunity to move beyond simply observing to actively influencing technology use. Both interventions used in this study — robot identification and team identification - invoked greater emotional attachment to the robot, which led to better team performance and higher viability. It is also worth noting that both interventions were theoretically motivated. 
Accepted to the Journal of the Association of Information Systems (JAIS) June 2017

\section{Limitations}

Our study has several limitations. First, we did not vary the complexity or difficulty of the tasks. Research has shown that task type and interdependence can alter what is or is not important for team performance (Katz-Navon \& Erez, 2005; Stewart \& Barrick, 2000; Thompson, 2011). Does the importance of a team's emotional attachment increase or decrease as the task type or level of interdependence changes? Future studies could examine more complex collaborative tasks and interactions such as what happens when multiple team members employ one robot.

Second, individual team members built their own robots in our study. This was done to minimize the potential impact of robot-building becoming confounded with team-building. We did ensure that both team members had the same experience (i.e. same treatment). Nonetheless, we acknowledge that the separate building activity may not fully reflect the collaborative nature of some teams working with robots. Future studies should examine impacts when all team members build and interact with one robot together.

Third, we studied one particular type of robot operated by humans. However, there are many other types of robots. For example, the results of our study might vary with autonomous robots. It should also be noted that our manipulation was all or nothing: building vs. no-building and team identification vs. no team identification. Further studies could be conducted with varying degrees of each treatment. Fourth, we used robot building as a way to invoke emotional attachment via robot identification. But we acknowledge that this is not always possible. Future studies should examine other ways to invoke self-extension.

Fifth, although our teams consisted of two humans and two robots, we only examined the relationship between the participant and the robot used to accomplish the task. Future studies could examine the impact of the emotional attachment between individuals and also between each individual and his or her teammate's robot. In addition, we examined individuals employing 
Accepted to the Journal of the Association of Information Systems (JAIS) June 2017

collaborative technologies in a team setting. We did not explore the potential differences between the individual and team use of the collaborative technology. Future research could investigate the differences between team- and individual-level emotional attachment to and use of collaborative technology.

Finally, the age of our participants may have been a limitation. In this study, participants' mean age was 23; however, workers in organizations may be older. We also anticipate that workers in this age group are more likely to be impacted by the use of robots. Therefore, the age of our participants may have been appropriate for this study.

\section{Theoretical Implications}

This study has several implications for theories on teamwork and collaborative technologies. First, our findings highlight the need for theories that focus on collaboration through embodied physical actions. IS scholars are beginning to develop and test theories to explain attitudes and behaviors associated with EVA robots (see Mennecke et al., 2007). These studies pivot around how social presence associated with EVA robots and their environments can help us understand collaboration through these robots (Qiu \& Benbasat, 2010; Saunders et al., 2011; Suh et al., 2011). Yet there is a profound absence of such theorizing on or about the use of EPA robots as collaborative technologies. Going forward, this has the potential to hinder research on this emerging collaborative technology, which is becoming central to teamwork.

We should note that it is also unclear whether performance benefits associated with emotional attachment can be extended to other types of technology. In particular, does the embodied physical nature of EPA robots make a team's emotional attachment particularly important to the success of its teamwork with robots relative to other technologies? Does a team's emotional attachment to traditional technologies such as GSS or mobile devices have the same benefits? In this sense, results of this study highlight the need to develop theories around which embodied 
physical actions are likely to lead to more or less emotional attachment, and whether these extend to EVA robots.

Second, our study contributes to theory on collaborative technologies by demonstrating the need for such theories to incorporate the potential impact of the bond teams can develop with their collaborative technologies. This bond is what differentiates emotional attachment from other types of affect (Thomson et al., 2005; Zhang, 2013). Yet, our current theories have failed to account for how this bond or attachment could impact the success of teams working with collaborative technologies. In this absence of theory, we have not begun to fully understand the impacts of what may prove to be a much more intimate relationship between teams and their technologies than studied traditionally. To begin to address this issue, future research could investigate what factors lead to the breakdown of this bond or how to repair it.

It is also not clear how emotional attachment might complement or undermine the impact of other theories used to understand collaborative technologies. For example, can a team's emotional attachment to its collaborative technology be explained by task technology fit (TTF) (see Zigurs \& Buckland, 1998)? Do teams become more emotionally attached to collaboration technologies that fit? Or can a team's emotional attachment to its collaborative technology be used to explain when TTF is likely not to predict performance? That is, fit might not be important when teams are emotionally attached to their technology. Our findings suggest that more research is needed to examine such questions.

Third, this study has implications for theories of teamwork that focus on outcomes such as team viability. This study suggests that team members' feelings toward their technology could play a vital role in promoting these teams' viability. There has been much theorizing on the antecedents of team viability (e.g., Balkundi \& Harrison, 2006). These theories do not recognize a team's attachment to its collaborative technology as a potential driver of team viability. Yet 
Accepted to the Journal of the Association of Information Systems (JAIS) June 2017

technology use is a central aspect of work for many teams (Alnuaimi, Robert, \& Maruping, 2010). Future research should examine whether a team's emotional attachment to other collaborative technologies can also predict the team's viability.

Fourth, this study extends the theories on both team identification and the use of collaborative technologies. Our results suggest that team identification increases team performance and viability by determining attitudes and feelings toward a team's collaborative technology. Yet our current theories on both team identification and the use of collaborative technologies have failed to make this theoretical linkage. Results of this study bridge the theories of team identification with the theories of collaborative technology use. As a result, research questions regarding how to integrate team identification into our current theoretical models might prove vital to better predicting the use and performance of teams employing collaborative technologies. In addition, such theoretical models might also prove vital to better understanding the impacts of team identification.

\section{Practical Implications}

Organizations have long recognized the importance of managing teams and their technology. Academic and corporate educational programs are filled with frameworks and best practices to help managers address these issues. Less attention has been paid to understanding how to manage the relationships between teams and their technologies. Yet as robots become an integral part of teamwork, this is precisely what is needed. Results of this study have several implications for managers.

Managers of teams working with robots should devise ways to promote strong team bonds toward their robots to secure not only better performance but also team longevity. Our method of robot identification was used to invoke self-extension, but there could be more practical approaches for managers to employ. Managers should consider eliciting feedback from the 
team when planning how to incorporate robots into teamwork. For example, participatory design is a well-known collaborative design approach involving all stakeholders to ensure that the design outcome meets everyone's needs (Schuler \& Namioka, 1993). This design approach allows robots to reflect the team's needs and attitudes, which should help teams to develop emotional bonds with the robots.

Managers might also want to ensure that the bond is not too strong. When people develop strong bonds to artifacts they can feel a sense of loss when separated from those artifacts (Schifferstein \& Zwartkruis-Pelgrim, 2008; Schultz et al., 1989). This may be particularly true for EPA robots because individuals tend to unconsciously project personalities and intentions onto such robots (Carpenter, 2014; Kidd et al., 2006). This could be a problem when organizations match robots to a particular team for a short-term objective, for example. Too much attachment might reduce performance when teams are required to work with other robots (Carpenter, 2014). One approach would be to rotate EPA robots across teams to reduce the perception that one set of robots belongs solely to one particular team. Another is to ensure that the robots look less like a pet or human, and more like a machine in its physical form. Research has shown that the more human- or pet-like the robot looks, the more attached humans can become (Groom et al., 2009; Hiolle et al., 2012).

\section{Conclusion}

EPA robots are becoming an important collaboration technology for the work performed by many teams. However, there is much to learn regarding the factors that facilitate more effective teamwork with these robots. In this study, we found that a team's emotional attachment to its EPA robots is crucial for the promotion of team performance and viability. This study is an important starting point in our understanding of more effective teamwork with EPA robots. Nonetheless, future research is needed to build on these ideas and expand our understanding 
of collaboration through EPA robots. This is both an important and much understudied area in the IS literature.

\section{References}

Abrams, D., \& Hogg, M. A. (2006). Social identifications: A social psychology of intergroup relations and group processes. Routledge.

Ainsworth, M. D. S., Blehar, M. C., Waters, E., \& Wall, S. (2014). Patterns of attachment: A psychological study of the strange situation. Psychology Press.

Alnuaimi, O. A., Robert, L. P., \& Maruping, L. M. (2010). Team size, dispersion, and social loafing in technology-supported teams: A perspective on the theory of moral disengagement. Journal of Management Information Systems, 27(1), 203-230.

Anson, R., Bostrom, R., \& Wynne, B. (1995). An experiment assessing group support system and facilitator effects on meeting outcomes. Management Science, 41(2), 189-208.

Aron, A., \& Aron, E. N. (1997). Self-expansion motivation and including other in the self. In S. Duck (Ed.), Handbook of personal relationships: Theory, research and interventions $\left(2^{\text {nd }}\right.$ ed., pp. 251-270). Hoboken, NJ: John Wiley \& Sons.

Ashforth, B. E., Harrison, S. H., \& Corley, K. G. (2008). Identification in organizations: An examination of four fundamental questions. Journal of Management, 34(3), 325-374.

Bajwa, D. S., Lewis, L. F., Pervan, G., Lai, V. S., Munkvold, B. E., \& Schwabe, G. (2008). Factors in the global assimilation of collaborative information technologies: An exploratory investigation in five regions. Journal of Management Information Systems, 25(1), 131-166.

Balkundi, P., \& Harrison, D. A. (2006). Ties, leaders, and time in teams: Strong inference about network structure's effects on team viability and performance. Academy of Management Journal, 49(1), 49-68.

Barrick, M. R., Stewart, G. L., Neubert, M. J., \& Mount, M. K. (1998). Relating member ability and personality to work-team processes and team effectiveness. Journal of applied psychology, 83(3), 377.

Baumeister, R. F., \& Leary, M. R. (1995). The need to belong: desire for interpersonal attachments as a fundamental human motivation. Psychological bulletin, 117(3), 497.

Beane, M., \& Orlikowski, W. J. (2015). What difference does a robot make? The material enactment of distributed coordination. Organization Science, 26(6), 1553-1573.

Beaudry, A., \& Pinsonneault, A. (2010). The Other Side of Acceptance: Studying the Direct and Indirect Effects of Emotions on Information Technology Use. MIS quarterly, 34(4), 689710.

Becker, T. E., Billings, R. S., Eveleth, D. M., \& Gilbert, N. L. (1996). Foci and bases of employee commitment: Implications for job performance. Academy of management journal, 39(2), 464-482.

Belk, R. W. (1988). Possessions and the extended self. Journal of consumer research, 15(2), $139-168$.

Belk, R. W. (2013). Extended Self in a Digital World. Journal of Consumer Research, 40(3), 477-500.

Bell, S. T., \& Marentette, B. J. (2011). Team viability for long-term and ongoing organizational teams. Organizational Psychology Review, 2041386611405876.

Benbasat, I., \& Lim, L.-H. (1993). The effects of group, task, context, and technology variables on the usefulness of group support systems A meta-analysis of experimental studies. Small Group Research, 24(4), 430-462. 
Bergami, M., \& Bagozzi, R. P. (2000). Self-categorization, affective commitment and group selfesteem as distinct aspects of social identity in the organization. British Journal of Social Psychology, 39(4), 555-577.

Bhattacherjee, A. (2001). Understanding information systems continuance: An expectationconfirmation model. MIS quarterly, 25(3), 351-370.

Bishop, J. W., Scott, K. D., \& Burroughs, S. M. (2000). Support, commitment, and employee outcomes in a team environment. Journal of Management, 26(6), 1113-1132.

Bliese, P. D. (2000). Within-group agreement, non-independence, and reliability: Implications for data aggregation and analysis. In K. J. Klein \& S. W. J. Kozlowski (Eds.), Multilevel theory, research, and methods in organizations: Foundations, extensions, and new directions (pp. 349-381). San Francisco, CA: Jossey-Bass.

Branscombe, N. R., \& Wann, D. L. (1991). The positive social and self concept consequences of sports team identification. Journal of Sport \& Social Issues, 15(2), 115-127.

Broadbent, E., Stafford, R., \& MacDonald, B. (2009). Acceptance of healthcare robots for the older population: Review and future directions. International Journal of Social Robotics, 1(4), 319-330.

Brown, R., Condor, S., Mathews, A., Wade, G., \& Williams, J. (1986). Explaining intergroup differentiation in an industrial organization. Journal of Occupational Psychology, 59(4), 273-286.

Brown, S. A., Dennis, A. R., \& Venkatesh, V. (2010). Predicting collaboration technology use: Integrating technology adoption and collaboration research. Journal of Management Information Systems, 27(2), 9-54.

Brown, S. A., Fuller, R. M., \& Vician, C. (2004). Who's afraid of the virtual world? Anxiety and computer-mediated communication. Journal of the Association for Information Systems, $5(2), 2$.

Bruner, G. C., \& Kumar, A. (2005). Explaining consumer acceptance of handheld Internet devices. Journal of Business Research, 58(5), 553-558.

Burke, J. L., Murphy, R. R., Coovert, M. D., \& Riddle, D. L. (2004). Moonlight in Miami: Field study of human-robot interaction in the context of an urban search and rescue disaster response training exercise. Human-Computer Interaction, 19(1-2), 85-116.

Burton-Jones, A., \& Straub Jr, D. W. (2006). Reconceptualizing system usage: An approach and empirical test. Information Systems Research, 17(3), 228-246.

Carlson, J. R., \& Zmud, R. W. (1999). Channel expansion theory and the experiential nature of media richness perceptions. Academy of Management Journal, 42(2), 153-170.

Carpenter, J. (2014). Just Doesn't Look Right: Exploring the Impact of Humanoid Robot Integration into Explosive Ordnance Disposal Teams. In Robotics: Concepts, methodologies, tools, and applications. IGI Global.

Carpenter, J. (2016). Culture and Human-Robot Interaction in Militarized Spaces: A War Story. Routledge.

Carron, A. V., Bray, S. R., \& Eys, M. A. (2002). Team cohesion and team success in sport. Journal of sports sciences, 20(2), 119-126.

Carter, M., \& Grover, V. (2015). Me, My Self, and I (T): Conceptualizing Information Technology Identity and its Implications. MIS Quarterly, 39(4), 931-957.

Carter, M., Grover, V., \& Thatcher, J. B. (2013). Mobile devices and the self: Developing the concept of mobile phone identity. In Strategy, adoption, and competitive advantage of mobile services in the global economy (pp. 150-164). IGI Global.

Chidambaram, L., \& Jones, B. (1993). Impact of communication medium and computer support on group perceptions and performance: A comparison of face-to-face and dispersed meetings. MIS quarterly, 17(4), 465-491.

Chin, W. W., \& Gopal, A. (1995). Adoption intention in GSS: relative importance of beliefs. ACM SigMIS Database, 26(2-3), 42-64. 
Chun, J. S., Shin, Y., Choi, J. N., \& Kim, M. S. (2013). How does corporate ethics contribute to firm financial performance? The mediating role of collective organizational commitment and organizational citizenship behavior. Journal of Management, 39(4), 853-877.

Cinoğlu, H., \& Arıkan, Y. (2012). Self, identity and identity formation: From the perspectives of three major theories. Journal of Human Sciences, 9(2), 1114-1131.

Connell, P. M., \& Schau, H. (2013). The symbiosis model of identity augmentation: Selfexpansion and self-extension as distinct strategies. In The Routledge Companion to Identity and Consumption (p. 21).

Costa, P., Margarida Passos, A., \& Bakker, A. (2014). Empirical validation of the team work engagement construct. Journal of Personnel Psychology, 13(1), 34-45.

Crowell, J. A., Fraley, R. C., \& Shaver, P. R. (2008). Measurement of individual differences in adolescent and adult attachment. In J. Cassidy \& P. R. Shaver (Eds.), Handbook of attachment: Theory, research, and clinical applications ( $2^{\text {nd }}$ ed., pp. 599-634). New York, NY: Guilford Press.

Csikszentmihalyi, M., \& Halton, E. (1981). The meaning of things: Domestic symbols and the self. Cambridge University Press.

Daft, R. L., \& Lengel, R. H. (1986). Organizational information requirements, media richness and structural design. Management science, 32(5), 554-571.

Dainty, A. R., Bryman, A., Price, A. D., Greasley, K., Soetanto, R., \& King, N. (2005). Project affinity: The role of emotional attachment in construction projects. Construction Management and Economics, 23(3), 241-244.

Dautenhahn, K. (2007). Methodology and themes of human-robot interaction: A growing research field. International Journal of Advanced Robotic Systems, 4(1), 103-108.

Dautenhahn, K. (2013). Human-robot interaction. In The Encyclopedia of Human-Computer Interaction, 2nd Ed., Interaction Design Foundation.

Davis, F. D. (1986). A technology acceptance model for empirically testing new end-user information systems: Theory and results. Massachusetts Institute of Technology.

Dennis, A. R. (1996). Information exchange and use in small group decision making. Small Group Research, 27(4), 532-550.

Dennis, A. R., Fuller, R. M., \& Valacich, J. S. (2008). Media, tasks, and communication processes: A theory of media synchronicity. MIS quarterly, 32(3), 575-600.

Dennis, A. R., \& Kinney, S. T. (1998). Testing media richness theory in the new media: The effects of cues, feedback, and task equivocality. Information systems research, 9(3), 256-274.

Dennis, A. R., Nunamaker Jr, J. F., \& Vogel, D. R. (1990). A comparison of laboratory and field research in the study of electronic meeting systems. Journal of Management Information Systems, 7(3), 107-135.

Dennis, A. R., \& Reinicke, B. A. (2004). Beta versus VHS and the acceptance of electronic brainstorming technology. MIS Quarterly, 28(1), 1-20.

Dennis, A. R., Wixom, B. H., \& Vandenberg, R. J. (2001). Understanding fit and appropriation effects in group support systems via meta-analysis. MIS Quarterly, 25(2), 167-193.

Dittmar, H. (2011). Material and consumer identities. In Handbook of identity theory and research (pp. 745-769). Springer.

Dourish, P. (2001). Seeking a foundation for context-aware computing. Human-Computer Interaction, 16(2-4), 229-241.

Ducheneaut, N., Wen, M.-H., Yee, N., \& Wadley, G. (2009). Body and mind: a study of avatar personalization in three virtual worlds. In Proceedings of the SIGCHI Conference on Human Factors in Computing Systems (pp. 1151-1160). ACM.

Ekkekakis, P. (2013). The measurement of affect, mood, and emotion: A guide for healthbehavioral research. Cambridge University Press. 
Ellemers, N., Kortekaas, P., \& Ouwerkerk, J. W. (1999). Self-categorisation, commitment to the group and group self-esteem as related but distinct aspects of social identity. European journal of social psychology, 29(23), 371-389.

Evans, C. R., \& Dion, K. L. (2012). Group cohesion and performance a meta-analysis. Small Group Research, 43(6), 690-701.

Fong, T., Nourbakhsh, I., \& Dautenhahn, K. (2003). A survey of socially interactive robots. Robotics and autonomous systems, 42(3), 143-166.

Foo, M.-D., Sin, H.-P., \& Yiong, L.-P. (2006). Effects of team inputs and intrateam processes on perceptions of team viability and member satisfaction in nascent ventures. Strategic Management Journal, 27(4), 389-399.

Fornell, C., \& Larcker, D. F. (1981). Structural equation models with unobservable variables and measurement error: Algebra and statistics. Journal of Marketing Research, 18(3), 382388.

Franceschi, K., Lee, R. M., Zanakis, S. H., \& Hinds, D. (2009). Engaging Group E-Learning in Virtual Worlds. Journal of Management Information Systems, 26(1), 73-100.

Franke, N., \& Piller, F. T. (2003). Key research issues in user interaction with user toolkits in a mass customisation system. International Journal of Technology Management, 26(5-6), 578-599.

Frizell, S. (2014, December 1). Meet the Robots Shipping Your Amazon Orders. Time.

Funk, D. C., \& James, J. D. (2006). Consumer loyalty: The meaning of attachment in the development of sport team allegiance. Journal of Sport Management, 20(2), 189.

Gardner, H. K., \& Kwan, L. (2012). Expertise Dissensus: A Multi-level Model of Teams' Differing Perceptions about Member Expertise. Harvard Business School Boston, MA.

Gray, G. T., \& Wert-Gray, S. (2012). Customer retention in sports organization marketing: examining the impact of team identification and satisfaction with team performance. International Journal of Consumer Studies, 36(3), 275-281.

Groom, V., \& Nass, C. (2007). Can robots be teammates?: Benchmarks in human-robot teams. Interaction Studies, 8(3), 483-500.

Groom, V., Takayama, L., Ochi, P., \& Nass, C. (2009). I am my robot: The impact of robotbuilding and robot form on operators. In Human-Robot Interaction (HRI), 2009 4th ACM/IEEE International Conference on (pp. 31-36). IEEE.

Harrison, D. A., Price, K. H., \& Bell, M. P. (1998). Beyond relational demography: Time and the effects of surface-and deep-level diversity on work group cohesion. Academy of management journal, 41(1), 96-107.

Hiolle, A., Cañamero, L., Davila-Ross, M., \& Bard, K. A. (2012). Eliciting caregiving behavior in dyadic human-robot attachment-like interactions. ACM Transactions on Interactive Intelligent Systems (TiiS), 2(1), 3.

Hoegl, M., Weinkauf, K., \& Gemuenden, H. G. (2004). Interteam coordination, project commitment, and teamwork in multiteam R\&D projects: A longitudinal study. Organization science, 15(1), 38-55.

Hogg, M. A., Abrams, D., Otten, S., \& Hinkle, S. (2004). The social identity perspective intergroup relations, self-conception, and small groups. Small group research, 35(3), 246-276.

Hogg, M. A., \& Turner, J. C. (1985). Interpersonal attraction, social identification and psychological group formation. European Journal of Social Psychology, 15(1), 51-66.

Hornsey, M. J., \& Hogg, M. A. (2000). Assimilation and diversity: An integrative model of subgroup relations. Personality and Social Psychology Review, 4(2), 143-156.

Huang, L., Varnado, T., \& Gillan, D. (2013). An exploration of robot builders' attachment to their LEGO robots. In Proceedings of the Human Factors and Ergonomics Society Annual Meeting (Vol. 57, pp. 1825-1829). SAGE Publications. 
Huettermann, H., Doering, S., \& Boerner, S. (2016). Understanding the development of team identification: A qualitative study in UN peacebuilding teams. Journal of Business and Psychology, 32(2), 217-234.

Janssen, O., \& Huang, X. (2008). Us and me: Team identification and individual differentiation as complementary drivers of team members' citizenship and creative behaviors. Journal of Management, 34(1), 69-88.

Jarvenpaa, S. L., Knoll, K., \& Leidner, D. E. (1998). Is anybody out there? Antecedents of trust in global virtual teams. Journal of management information systems, 14(4), 29-64.

Kang, S., Lim, K. H., Kim, M. S., \& Yang, H.-D. (2012). Research note - A Multilevel Analysis of the Effect of Group Appropriation on Collaborative Technologies Use and Performance. Information Systems Research, 23(1), 214-230.

Katz-Navon, T. Y., \& Erez, M. (2005). When collective- and self-efficacy affect team performance: The role of task interdependence. Small Group Research, 36(4), 437-465.

Kidd, C. D., Taggart, W., \& Turkle, S. (2006). A sociable robot to encourage social interaction among the elderly. In Robotics and Automation, 2006. ICRA 2006. Proceedings 2006 IEEE International Conference on (pp. 3972-3976). IEEE.

Kiesler, T., \& Kiesler, S. (2004). My pet rock and me: An experimental exploration of the self extension concept. Human-Computer Interaction Institute, 85.

Kim, C. K., Han, D., \& Park, S.-B. (2001). The effect of brand personality and brand identification on brand loyalty: Applying the theory of social identification. Japanese Psychological Research, 43(4), 195-206.

Kim, H.-W., Chan, H., Chan, Y., \& Gupta, S. (2004). Understanding the balanced effects of belief and feeling on information systems continuance. In AIS 2004 Proceedings.

Kim, K., Schmierbach, M. G., Bellur, S. (Saras), Chung, M.-Y., Fraustino, J. D., Dardis, F., \& Ahern, L. (2015). Is it a sense of autonomy, control, or attachment? Exploring the effects of in-game customization on game enjoyment. Computers in Human Behavior, 48, 695705.

Klein, H. J., \& Mulvey, P. W. (1995). Two investigations of the relationships among group goals, goal commitment, cohesion, and performance. Organizational Behavior and Human Decision Processes, 61(1), 44-53.

Kleine, S. S., Kleine, R. E., \& Allen, C. T. (1995). How is a possession "me" or "not me"? Characterizing types and an antecedent of material possession attachment. Journal of Consumer Research, 22(3), 327-343.

Kozlowski, S. W., \& Klein, K. J. (2000). A multilevel approach to theory and research in organizations: Contextual, temporal, and emergent processes. In K. J. Klein \& S. W. J. Kozlowski (Eds.), Multilevel theory, research and methods in organizations: Foundations, extensions, and new directions (pp. 3-90). San Francisco, CA: JosseyBass.

Krämer, N. C., von der Pütten, A., \& Eimler, S. (2012). Human-Agent and Human-Robot Interaction Theory: Similarities to and Differences from Human-Human Interaction. In Human-Computer Interaction: The Agency Perspective (pp. 215-240). Springer.

Kruijff, G.-J. M., Janíček, M., Keshavdas, S., Larochelle, B., Zender, H., Smets, N. J., ... Sulk, M. (2014). Experience in system design for human-robot teaming in urban search and rescue. In Field and Service Robotics (pp. 111-125). Springer.

Kwon, H. H., \& Armstrong, K. L. (2004). An exploration of the construct of psychological attachment to a sport team among college students: A multidimensional approach. Sport Marketing Quarterly, 13(2), 94-103.

Kwon, H. H., Trail, G., \& James, J. D. (2007). The mediating role of perceived value: Team identification and purchase intention of team-licensed apparel. Journal of Sport Management, 21(4), 540. 
Lee, K. M., Jung, Y., Kim, J., \& Kim, S. R. (2006). Are physically embodied social agents better than disembodied social agents?: The effects of physical embodiment, tactile interaction, and people's loneliness in human-robot interaction. International Journal of HumanComputer Studies, 64(10), 962-973.

Lee, M. K., Kiesler, S., Forlizzi, J., \& Rybski, P. (2012). Ripple effects of an embedded social agent: A field study of a social robot in the workplace. In Proceedings of the SIGCHI Conference on Human Factors in Computing Systems (pp. 695-704). ACM.

Li, D., Browne, G. J., \& Chau, P. Y. (2006). An Empirical Investigation of Web Site Use Using a Commitment-Based Model. Decision Sciences, 37(3), 427-444.

Li, D., Browne, G. J., \& Wetherbe, J. C. (2006). Why do internet users stick with a specific web site? A relationship perspective. International Journal of Electronic Commerce, 10(4), 105-141.

Li, D., Rau, P. P., \& Li, Y. (2010). A cross-cultural study: Effect of robot appearance and task. International Journal of Social Robotics, 2(2), 175-186.

Littrell, M. A., Anderson, L. F., \& Brown, P. J. (1993). What makes a craft souvenir authentic? Annals of Tourism Research, 20(1), 197-215.

Ljungblad, S., Kotrbova, J., Jacobsson, M., Cramer, H., \& Niechwiadowicz, K. (2012). Hospital robot at work: Something alien or an intelligent colleague? In Proceedings of the ACM 2012 conference on Computer Supported Cooperative Work (pp. 177-186). ACM.

Malhotra, Y., \& Galletta, D. F. (1999). Extending the technology acceptance model to account for social influence: Theoretical bases and empirical validation. In Proceedings of the 32nd Annual Hawaii International Conference on Systems Sciences, 1999. HICSS-32 (Vol. Track1, p. 14 pp.-).

Maruping, L. M., Bala, H., Venkatesh, V., \& Brown, S. A. (2017). Going beyond intention: Integrating behavioral expectation into the unified theory of acceptance and use of technology. Journal of the Association for Information Science and Technology, 68(3), 623-637.

McLeod, P. L. (1992). An assessment of the experimental literature on electronic support of group work: Results of a meta-analysis. Human-Computer Interaction, 7(3), 257-280.

Mennecke, B., Roche, E. M., Bray, D. A., Konsynski, B., Lester, J., Rowe, M., \& Townsend, A. M. (2007). Second Life and other virtual worlds: A roadmap for research. In 28th International Conference on Information Systems (ICIS).

Mennecke, B., Triplett, J. L., Hassall, L. M., Conde, Z. J., \& Heer, R. (2011). An examination of a theory of embodied social presence in virtual worlds. Decision Sciences, 42(2), 413450.

Meyer, J. P., Becker, T. E., \& Van Dick, R. (2006). Social identities and commitments at work: Toward an integrative model. Journal of Organizational Behavior, 27(5), 665-683.

Meyer, J. P., Paunonen, S. V., Gellatly, I. R., Goffin, R. D., \& Jackson, D. N. (1989). Organizational commitment and job performance: It's the nature of the commitment that counts. Journal of applied Psychology, 74(1), 152.

Meyer, J. P., Stanley, D. J., Herscovitch, L., \& Topolnytsky, L. (2002). Affective, continuance, and normative commitment to the organization: A meta-analysis of antecedents, correlates, and consequences. Journal of vocational behavior, 61(1), 20-52.

Mikulincer, M., Orbach, I., \& lavnieli, D. (1998). Adult attachment style and affect regulation: Strategic variations in subjective self-other similarity. Journal of Personality and Social Psychology, 75(2), 436.

Mortenson, M. J., \& Vidgen, R. (2016). A computational literature review of the technology acceptance model. International Journal of Information Management, 36(6, Part B), 1248-1259.

Mugge, R., Schoormans, J. P., \& Schifferstein, H. N. (2009). Emotional bonding with personalised products. Journal of Engineering Design, 20(5), 467-476. 
Nomura, T., Suzuki, T., Kanda, T., \& Kato, K. (2006). Measurement of negative attitudes toward robots. Interaction Studies, 7(3), 437-454.

Park, S.-H., Lee, L., \& Yi, M. Y. (2011). Group-level effects of facilitating conditions on individual acceptance of information systems. Information Technology and Management, 12(4), 315-334.

Pearsall, M. J., \& Venkataramani, V. (2015). Overcoming asymmetric goals in teams: The interactive roles of team learning orientation and team identification. Journal of Applied Psychology, 100(3), 735.

Pierce, J. L., Kostova, T., \& Dirks, K. T. (2001). Toward a theory of psychological ownership in organizations. Academy of management review, 26(2), 298-310.

Porter, T. W., \& Lilly, B. S. (1996). The effects of conflict, trust, and task commitment on project team performance. International Journal of Conflict Management, 7(4), 361-376.

Prentice, D. A., Miller, D. T., \& Lightdale, J. R. (1994). Asymmetries in attachments to groups and to their members: Distinguishing between common-identity and common-bond groups. Personality and Social Psychology Bulletin, 20(5).

Qiu, L., \& Benbasat, I. (2010). A study of demographic embodiments of product recommendation agents in electronic commerce. International Journal of HumanComputer Studies, 68(10), 669-688.

Rae, I., Takayama, L., \& Mutlu, B. (2012). One of the gang: supporting in-group behavior for embodied mediated communication. In Proceedings of the SIGCHI Conference on Human Factors in Computing Systems (pp. 3091-3100). ACM.

Ramiller, N. (2016). New Technology and the Post-Human Self: Rethinking Appropriation and Resistance. ACM SIGMIS Database: the DATABASE for Advances in Information Systems, 47(4), 23-33.

Ratcheva, V., \& Vyakarnam, S. (2001). Exploring team formation processes in virtual partnerships. Integrated Manufacturing Systems, 12(7), 512-523.

Read, W., Robertson, N., \& McQuilken, L. (2011). A novel romance: The technology acceptance model with emotional attachment. Australasian Marketing Journal (AMJ), 19(4), 223229.

Richter, A. W., West, M. A., Van Dick, R., \& Dawson, J. F. (2006). Boundary spanners' identification, intergroup contact, and effective intergroup relations. Academy of Management Journal, 49(6), 1252-1269.

Robert, L. P. (2013). A multi-level analysis of the impact of shared leadership in diverse virtual teams. In Proceedings of the 2013 conference on Computer supported cooperative work (pp. 363-374). ACM.

Robert, L. P., \& Dennis, A. R. (2005). Paradox of richness: A cognitive model of media choice. Professional Communication, IEEE Transactions on, 48(1), 10-21.

Robert, L. P., Dennis, A. R., \& Ahuja, M. K. (2008). Social Capital and Knowledge Integration in Digitally Enabled Teams. Information Systems Research, 19(3), 314-334.

Robert, L. P., \& You, S. (2014). Human-Robot Interaction in Groups: Theory, Method, and Design for Robots in Groups. In Proceedings of the 18th International Conference on Supporting Group Work (pp. 310-312). New York, NY, USA: ACM.

Rom, E., \& Mikulincer, M. (2003). Attachment theory and group processes: The association between attachment style and group-related representations, goals, memories, and functioning. Journal of personality and social psychology, 84(6), 1220.

Roto, V., \& Rautava, M. (2008). User experience elements and brand promise. In International Engagability \& Design Conference, in conjunction with NordiCHI.

Russell, J. A. (2003). Core affect and the psychological construction of emotion. Psychological review, 110(1), 145. 
Sarker, S., \& Valacich, J. S. (2010). An alternative to methodological individualism: A nonreductionist approach to studying technology adoption by groups. MIS Quarterly, 34(4), 779-808.

Saunders, C. S., Rutkowski, A.-F., Van Genuchten, M., Vogel, D., \& Orrego, J. M. (2011). Virtual Space and Place: Theory and Test. MIS Quarterly, 35(4), 1079-1098.

Scheutz, M. (2011). The Inherent Dangers of Unidirectional Emotional Bonds between Humans and Social Robots. Robot Ethics: The Ethical and Social Implications of Robotics, 205.

Schifferstein, H. N., \& Zwartkruis-Pelgrim, E. P. (2008). Consumer-product attachment: Measurement and design implications. International Journal of Design, 2(3), 1-13.

Schmitt, M. T., Spears, R., \& Branscombe, N. R. (2003). Constructing a minority group identity out of shared rejection: The case of international students. European Journal of Social Psychology, 33(1), 1-12.

Schouten, J. W., \& McAlexander, J. H. (1995). Subcultures of consumption: An ethnography of the new bikers. Journal of consumer research, 22(1), 43-61.

Schuler, D., \& Namioka, A. (1993). Participatory design: Principles and practices. CRC Press.

Schultz, S. E., Kleine, R. E., \& Kernan, J. B. (1989). 'These are a few of my favorite things': Toward an explication of attachment as a consumer behavior construct. Advances in Consumer Research, 16(1), 359-366.

Shah, J., Wiken, J., Williams, B., \& Breazeal, C. (2011). Improved Human-robot Team Performance Using Chaski, a Human-inspired Plan Execution System. In Proceedings of the 6th International Conference on Human-robot Interaction (pp. 29-36). New York, NY, USA: ACM.

Shamir, B., \& Lapidot, Y. (2003). Trust in organizational superiors: Systemic and collective considerations. Organization studies, 24(3), 463-491.

Sharda, R., Barr, S. H., \& McDonnell, J. C. (1988). Decision Support System Effectiveness: A Review and an Empirical Test. Management Science, 34(2), 139-159.

Slater, J. S. (2001). Collecting brand loyalty: A comparative analysis of how Coca-Cola and Hallmark use collecting behavior to enhance brand loyalty. Advances in Consumer Research, 28, 362-369.

Smith, A., Graetz, B., \& Westerbeek, H. (2008). Sport sponsorship, team support and purchase intentions. Journal of Marketing Communications, 14(5), 387-404.

Somech, A., Desivilya, H. S., \& Lidogoster, H. (2009). Team conflict management and team effectiveness: The effects of task interdependence and team identification. Journal of Organizational Behavior, 30(3), 359-378.

Sonnentag, S., \& Frese, M. (2003). Stress in organizations. Wiley Online Library.

Stewart, G. L., \& Barrick, M. R. (2000). Team structure and performance: Assessing the mediating role of intrateam process and the moderating role of task type. Academy of management Journal, 43(2), 135-148.

Stryker, S., \& Burke, P. J. (2000). The past, present, and future of an identity theory. Social psychology quarterly, 63(4), 284-297.

Suh, K.-S., Kim, H., \& Suh, E. K. (2011). What if your avatar looks like you? Dual-congruity perspectives for avatar use. MIS Quarterly, 35(3), 711-729.

Sundstrom, E., De Meuse, K. P., \& Futrell, D. (1990). Work teams: Applications and effectiveness. American psychologist, 45(2), 120.

Sung, J.-Y., Guo, L., Grinter, R. E., \& Christensen, H. I. (2007). 'My Roomba Is Rambo': Intimate Home Appliances. Springer.

Tajfel, H., \& Turner, J. C. (1979). An integrative theory of intergroup conflict. The social psychology of intergroup relations, 33(47), 74.

Tajfel, H., \& Turner, J. C. (2004). The Social Identity Theory of Intergroup Behavior. Social Science Information, 13(2). 
Thatcher, J. B., \& Perrewe, P. L. (2002). An empirical examination of individual traits as antecedents to computer anxiety and computer self-efficacy. MIS Quarterly, 26(4), 381396.

Thompson, J. D. (2011). Organizations in action: Social science bases of administrative theory (Vol. 1). Transaction publishers.

Thomson, M., Maclnnis, D. J., \& Whan Park, C. (2005). The ties that bind: Measuring the strength of consumers' emotional attachments to brands. Journal of Consumer Psychology, 15(1), 77-91.

Thrun, S. (2004). Toward a framework for human-robot interaction. Human-Computer Interaction, 19(1-2), 9-24.

Tsui, A. S., Egan, T., \& O'Reilly, C. (1991). Being different: Relational demography and organizational attachment. In Academy of Management Proceedings (Vol. 1991, pp. 183-187). Academy of Management.

Turkle, S. (2010). In good company? On the threshold of robotic companions. Close Engagements with Artificial Companions: Key Social, Psychological, Ethical and Design Issues. Amsterdam, The Netherlands: John Benjamins Publishing Company, 3-10.

Van Der Vegt, G. S., \& Bunderson, J. S. (2005). Learning and performance in multidisciplinary teams: The importance of collective team identification. Academy of Management Journal, 48(3), 532-547.

Van Dyne, L., \& Pierce, J. L. (2004). Psychological ownership and feelings of possession: Three field studies predicting employee attitudes and organizational citizenship behavior. Journal of Organizational Behavior, 25(4), 439-459.

Venkatesh, V., \& Bala, H. (2008). Technology acceptance model 3 and a research agenda on interventions. Decision sciences, 39(2), 273-315.

Venkatesh, V., Morris, M. G., Davis, G. B., \& Davis, F. D. (2003). User acceptance of information technology: Toward a unified view. MIS quarterly, 27(3), 425-478.

Vincent, J. (2006). Emotional attachment and mobile phones. Knowledge, Technology \& Policy, 19(1), 39-44.

Wallendorf, M., \& Arnould, E. J. (1988). 'My Favorite Things': A Cross-Cultural Inquiry into Object Attachment, Possessiveness, and Social Linkage. Journal of Consumer Research, 14(4), 531-547.

Weick, K. E. (1995). Sensemaking in organizations (Vol. 3). Sage.

Weick, K. E., Sutcliffe, K. M., \& Obstfeld, D. (2005). Organizing and the process of sensemaking. Organization science, 16(4), 409-421.

Wright, K. M., Ursano, R. J., Bartone, P. T., \& Ingraham, L. H. (1990). The shared experience of catastrophe: An expanded classification of the disaster community. American Journal of Orthopsychiatry, 60(1), 35.

Wu, S.-H., Tsai, C.-Y. D., \& Hung, C.-C. (2012). Toward team or player? How trust, vicarious achievement motive, and identification affect fan loyalty. Journal of Sport Management, 26(2), 177-191.

Yanco, H. A., Norton, A., Ober, W., Shane, D., Skinner, A., \& Vice, J. (2015). Analysis of Human-robot Interaction at the DARPA Robotics Challenge Trials. Journal of Field Robotics, 32(3), 420-444.

You, S., Nie, J., Suh, K., \& Sundar, S. S. (2011). When the robot criticizes you...: self-serving bias in human-robot interaction. In Proceedings of the 6th international conference on Human-robot interaction (pp. 295-296). ACM.

You, S., \& Sundar, S. S. (2013). I feel for my avatar: Embodied perception in VEs. In Proceedings of the SIGCHI Conference on Human Factors in Computing Systems (pp. 3135-3138). ACM. 
Zawieska, K., \& Duffy, B. R. (2014). Human-Robot Exploration. In Robot and Human Interactive Communication, 2014 RO-MAN: The 23rd IEEE International Symposium on (pp. 808813). IEEE.

Zhang, P. (2013). The affective response model: A theoretical framework of affective concepts and their relationships in the ICT context. MIS Quarterly, 37(1), 247-274.

Zhang, P., \& Li, N. (2005). The importance of affective quality. Communications of the ACM, 48(9), 105-108.

Ziemke, T. (2003). What's that thing called embodiment? In Proceedings of the 25th Annual meeting of the Cognitive Science Society (pp. 1305-1310). Citeseer.

Zigurs, I., \& Buckland, B. K. (1998). A theory of task/technology fit and group support systems effectiveness. MIS quarterly, 22(3), 313-334. 


\section{Appendix - List of all measurement items}

\section{Table A.1: Measurement Items}

\begin{tabular}{|c|c|}
\hline Constructs & Items \\
\hline \multirow{7}{*}{ Self-extension } & This robot reminds me of who I am. \\
\hline & $\begin{array}{l}\text { If I lost this robot, I would feel like I had lost a little bit of } \\
\text { myself. }\end{array}$ \\
\hline & $\begin{array}{l}\text { If I were describing myself to my team members, this robot } \\
\text { would likely be something I would mention. }\end{array}$ \\
\hline & If someone ridiculed this robot, I would feel irritated. \\
\hline & $\begin{array}{l}\text { If someone destroyed this robot, I would feel a little bit } \\
\text { personally attacked. }\end{array}$ \\
\hline & $\begin{array}{l}\text { If someone praised this robot, I would feel somewhat } \\
\text { praised myself. }\end{array}$ \\
\hline & $\begin{array}{l}\text { If I didn't have this robot, I would feel a little bit less like } \\
\text { myself. }\end{array}$ \\
\hline \multirow{6}{*}{ Team Identification } & I was happy to be a member of this team. \\
\hline & I liked the other team members including robots. \\
\hline & I had a strong sense of belonging toward the team. \\
\hline & $\begin{array}{l}\text { I was happy with being identified as a member of this } \\
\text { team. }\end{array}$ \\
\hline & I liked being identified as a member of this team. \\
\hline & I considered myself a part of this team. \\
\hline \multirow{7}{*}{$\begin{array}{l}\text { Emotional Attachment to } \\
\text { Robots }\end{array}$} & I feel emotionally connected to this robot. \\
\hline & This robot is dear to me. \\
\hline & I bonded with this robot. \\
\hline & This robot has some meaning for me. \\
\hline & I am attached to this robot. \\
\hline & This robot is special to me. \\
\hline & I have some feelings for this robot. \\
\hline \multirow{2}{*}{ Team Viability } & $\begin{array}{l}\text { This team including the robots would perform well together } \\
\text { in the future. }\end{array}$ \\
\hline & $\begin{array}{l}\text { If I had the choice of working on this team including the } \\
\text { robots again, I would do it. }\end{array}$ \\
\hline
\end{tabular}




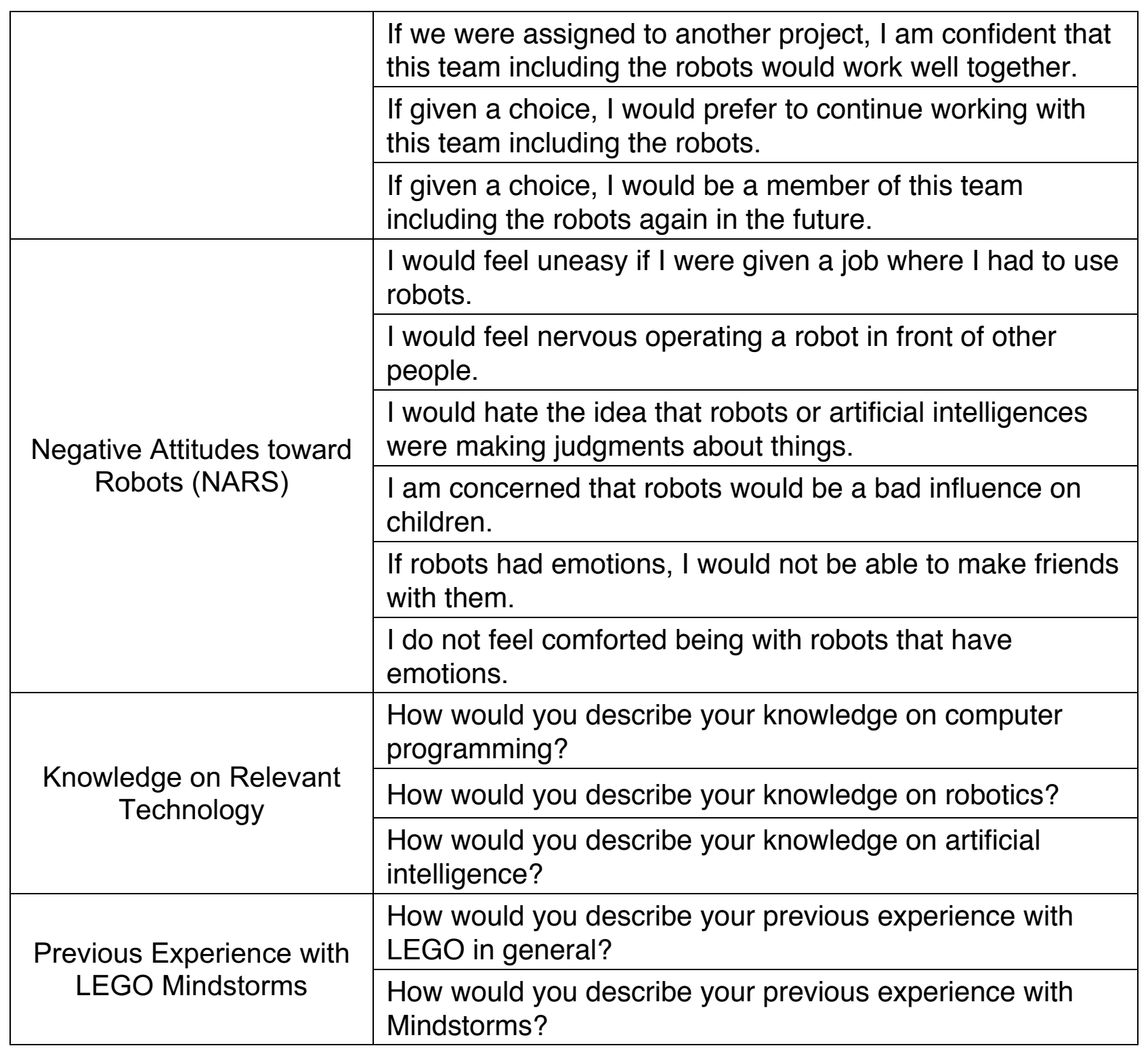

